\title{
THERMAL MODELING IN A SIMULATED SPACE ENVIRONMENT
}

\author{
By \\ PAUL LEROY MILIER, JR。 \\ Bachelor of Science \\ Kansas State University \\ Manhattan, Kansas \\ 1957 \\ Master of Science \\ Kansas State University \\ Manhattan, Kansas \\ 1961
}
Submitted to the Faculty of the
Graduate College of the
Oklahoma State University
in partial fulfillment of
the requirements for
the Degree of
DOCTOR OF PHILOSOPHY
July, 1966


THERMAL MODELING IN A SIMULATED SPACE ENVIRONMENT

Thesis Approved:
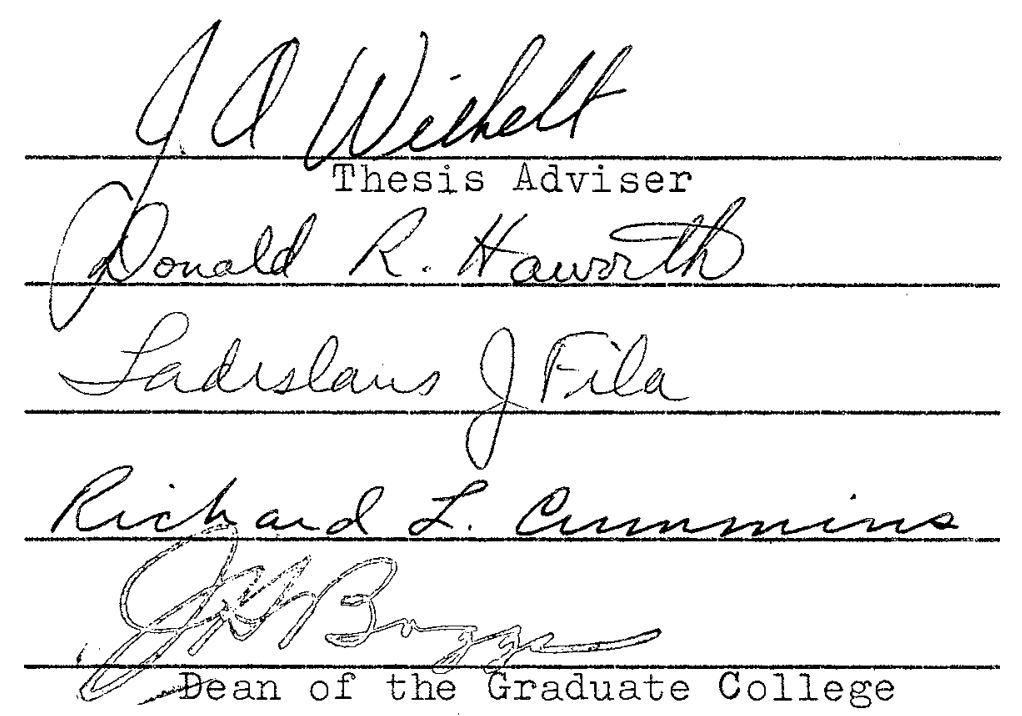

628114 


\section{ACKIOWLEDGMENT}

My sincere appreciation and gratitude is extended to the following individuals and organizations:

Dr. J. A. Wiebelt, who served as major adviser and committee chairman. His interest, encouragement, and guidance were invaluable during my two years of graduate study at Oklahoma State University.

My graduate committee, composed of Professors D. R. Haworth, I. J. Fila, and R. I. Cummins, who rendered guidance and counsel.

Kansas State University for providing a sabbatical leave and the National Science Foundation for financial support.

Major J. D. Pinson for his daily encouragement and friendship.

Miss Velda Davis for her typing of the manuscript.

My wife, Roseann, for her many years of encouragement and sacrifice during my graduate study, and daughter, Janet Leigh, for arriving on the scene and providing captivating periods of relaxation. 
TABLE OF CONTENTS

Chapter

Page

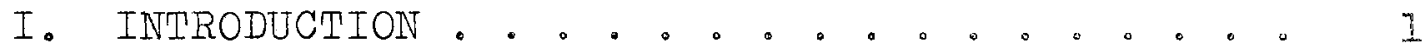

II. DIMENSIONAL ANALYSIS - . . . . . . . 。 3

Derivation of the Similarity

Parameters ............. . 4

Solid Conduction ......... 4

Interfacial Conaution . . . . . 5

Internal Heat Generation . . . . 6

Internal Energy Changes . . . . 6

Emitted Radiation ......... 6

Absorbed Radiation........ ?

Formation of the Similarity

Parameters.......... 8

An Alternate Derivation of the

Similarity Parameters . . . . . . . 15

Property Variations With Temperature 。. 17

The Similarity Parameters ....... 20

Application to Joined Materials..... 22

Verification of Results . . . . .... 24

Discussion of Assumptions ....... 25

II. A SURVEY OF THE IITERATURE 。 . . . . . . . 29

IV. EXPERIMENTAL PROGRAM -. . . . . . . 36

Model Design and Construction ..... 35

Support Equipment .。........ 41

Experimental Procedure 。. . .... 44

V. EXPERIMENTAI RESUITS 。. . . . . . 。. . 45

Steady-State Results .......... 45

Transient Results.。.。..。. . . 53

Error Analysis .......... 56

Incorrect Energy Input ......66 66

Thermocouple and Support Wire

Losses............. 67

Heater Insulation Losses... . . 68

Heater Lead Losses . . . . . . 68

Variation of Thermal Properties . . 70 


\section{TABLE OF CONTENTS (Continued)}

Chapter Page

VI. CONCLUSIONS AND RECOMMENDATIONS . . . . . 75 SEIECTED BIBLIOGRAPHY . . . . . . . . . . . 78 APPENDIX I. SIMILARITY PARAMETERS FOR A FLAT PLATE AND A HOLLOW CYLINDER

80 
IIST OF TABLES

Table

Page

I. The Similarity Parameters . . . . . . . 21

II. Thermal Properties of Materials . . . . . 26

III. Thermai Constants . . . . . . . . . . 27

IV. Prototype and Model Dimensions, Single Material . . . . . . . . . 38

V. Prototype and Model Dimension, Two Materials 。. . . . . . . . . . 38

VI. Heater, Support, and Thermocouple Wire Gages ................440

VII. Calculated Values of Similarity Parameters: Single Material .............446

VIII. Calculated Values of Similarity Parameters, Two Materials . . . . . . . . . 46

IX. Steady-State Results, Single Material, Low Energy Input . . . . . . . 。. 4 ?

X. Steady-State Results, Single Material, High Energy Input 。. 。. 。. 。。 。 48

XI. Steady-State Results, Two Materials, Low Energy Input .............4 49

XII. Steady-State Results, Two Materials, High Energy Input ............ 50

XIII. Calculated Energy Losses, Single Material, Steady-State . . . . . . . . . . . 71

XIV. Calculated Energy Losses, Two Materials, Steady-State $0.0 .0 . . .0 .0 .72$ 


\section{IIST OF TABLES (Continued)}

Table $\quad$ Page

XV. Similarity Parameter Variations With Variations of $\mathrm{k}_{\mathrm{0}}^{*} \cdot$. . . . . . . . . 74

XVI. Similarity Parameters for Flat Plate and Hollow Cylindrical Systems . . . . . 86 


\section{IIST OF FIGURES}

Figure

Page

1. Temperature Versus Time, Single Material Prototype .. . . . . . . . .

2. Single Material Prototype Temperatures Predicted From Model 1-1, Method 2.... 58

3. Single Material Prototype Temperatures Predicted From Model 1-1, Method 3.... 59

4. Single Material Prototype Temperatures Predicted From Model 1-3, Method 2,60

5. Single Material Prototype Temperatures Predicted From Model 1-4, Method 2....61

6. Temperature Versus Time: Two Material Prototype.。.。............. 62

7. Two Material Prototype Temperatures
Predicted From Model 2-1........ 63

8. Two Material Prototype Temperatures Predicted From Model 2-2, Test 1..... 64

9. Two Material Prototype Temperatures Predicted From Model 2-2, Test 2。 2.05 


\section{IIST OF SYMBOIS}

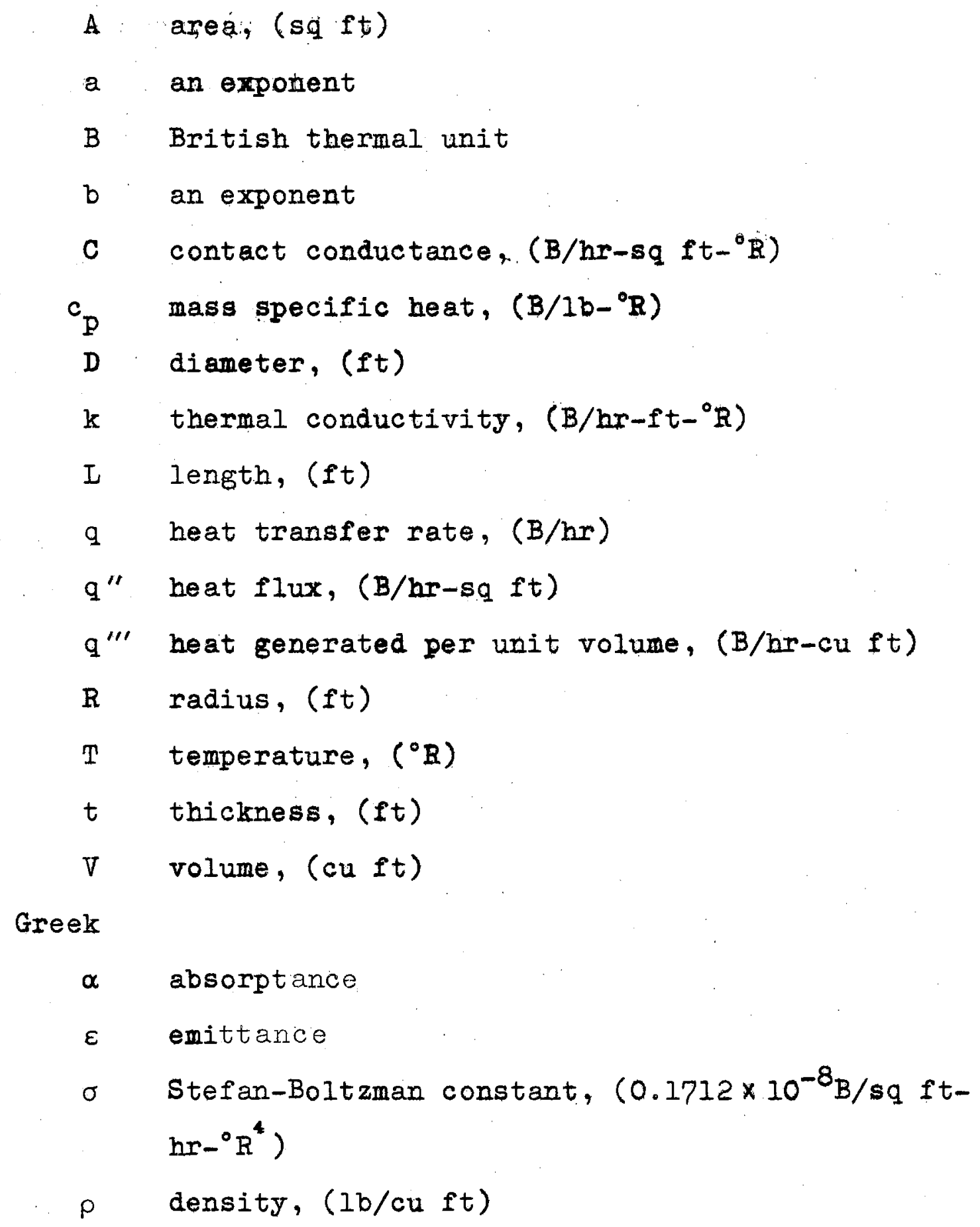




\section{LIST OF SYMBOIS (Continued)}

$$
\begin{aligned}
& \varphi \text { radiative heat } f l u x,(B / h r-s q f t) \\
& \theta \text { time, (hours) }
\end{aligned}
$$

Subscripts

$\begin{aligned} i, j, k & \text { regions of uniform temperature } \\ n & \text { normal direction } \\ \text { o } & \text { reference or constant value } \\ \text { m } & \text { model } \\ \text { p } & \text { prototype } \\ \text { s } & \text { surface }\end{aligned}$




\section{CHAPTER I}

\section{INTRODUCTION}

One of the problems in the design of spacecraft is the prediction of temperatures and temperature gradients within the spacecraft while in its operating environment. The present method of solving this problem is by performance tests on afull sized prototype of the spacecraft in a space simulation chamber. This procedure has become difficult because of the increased size of spacecraft, making necessary a correspondingly large test chamber with its attendant complexity and cost, and will become virtually impossible with the advent of larger spacecraft and manned space stations.

Another solution to the problem is thermal modeling. As suggested by Vickers (1), a thermal model may be defined as a model different in size (generally smaller) than its prototype, which under suitable conditions will predict accurately the thermal behavior of its prototype.

The mission of the spacecraft to be modeled determines the conditions which are imposed on the model. Some parts of the mission may be long periods of interplanetary travel and may be considered as steady state conditions. 
Conditions imposed by launch, mid-course maneuvers, and planetary encounter may involve transient conditions for which temperatures and temperature gradients must be determined.

Considerable analytical and experimental work has been done in the area of thermal modeling for steady state conditions imposed on conduction-radiation coupled systems. However, relatively little work has been accomplished in the study of transient behavior of thermal models and the need for such a study is readily apparent.

The objective of this dissertation was to investigate the applicability of thermal modeling to steady state and transient conditions, for both single and multiple material systems, taking into account changes of material properties with temperature. Space conditions were simulated by high vacuum and low temperature boundary conditions. Simulated solar or particle radiation was not attempted. 


\section{CHAPTER II}

\section{DIMENSIONAL ANALYSIS}

The basis for thermal modeling of a physical system is the maintenance of thermal similitude between prototype and model. Thermal similitude is maintained by preserving the numerical equality of certain dimensionless groups of properties of the prototype and model. These dimensionless groups, or similarity parameters, must together contain all the physical quantities which interact to determine the thermal behavior of the system. One method of deriving the similarity parameters used in thermal modeling is based on the experience and intuition of the experimenter. Needless to say, this requires a complete understanding of the physical phenomena involved.

A second method of deriving the parameters is to depend upon the differential equations describing the thermal behavior of the spacecraft to provide the parameters. Since the differential equations for radiation-conduction coupled systems are well known (but not necessarily solvable), this approach is less likely to involve difficulty for the inexperienced. Both of these methods have been used by previous authors, resulting in the same set 
of similarity parameters $(2,3,4,7)$. It should be noted that experimental success with these parameters is the only method of proving their value.

The intuitive approach to deriving the similarity parameters presents a better physical picture of the phem nomena involved and will be used in the following section.

\section{Derivation of the Similarity Parameters}

The intuitive approach to deriving the similarity parameters is best illustrated with a method similar to that used by Fowle and Gabron (4). The following heat transfer phenomena are to be considered:

1. Head transfer by solid conduction.

2. Heat transfer at solid-to-solid interfaces.

3. Heat generated by internal sources.

4. Internal energy changes during transients.

5. Heat transfer by emitted radiation.

6. Heat transfer by absorbed radiation.

\section{Solid Conduction}

Heat transfer (energy per unit time) by solid conduc tion is characterized by the thermal conductivity of the material, an area normal to the direction of heat flow, and the temperature gradient existing in the material. Generally, it has been found that the thermal conductivity of a material is a temperature dependent property. The 
one dimensional conduction heat transfer is expressed by:

$$
q=k A_{n} \frac{d T}{d I} .
$$

Interfacial Conduction

Heat transfer at solid-to-solid interfaces introduces the concept of thermal contact conductance. The thermal contact conductance is defined as the ratio of the heat flux (energy per unit area per unit time) to the temperature difference across the contact region. The value of the thermal contact conductance in a vacuum depends on the structural characteristics of the joined materials, on their surface finish, and on the contact pressure. The interfacial conduction may be expressed as follows:

$$
q=A_{n} C \Delta T \text {. }
$$

Because of the difficulties involved in determining the value of the contact conductance, a subject on which much research has been done and about which very little in the way of reproducible results have been determined, all joints between materials used in this experimental work were high conductivity soldered joints. This, in effect, eliminated the need to consider a separate equation for joints because there was continuity of heat transfer rate and temperature across the joint. 


\section{Internal Heat Generation}

The heat generated by internal sources is generally of the $I^{2} R$ variety and may be represented in heat transfer rate form by the product of the heat generated per unit volume per unit time and a characteristic volume:

$$
q=q^{\prime \prime} V=q^{\prime \prime} A_{n} I .
$$

\section{Internal Energy Changes}

The change of internal energy during a transient introduces the concept of thermal inertia, a characteristic described by the volume specific heat (a property, most often expressed as the product of the mass specific heat and the material density), divided by the time differential. The rate of internal energy change may be expressed in heat transfer rate form by multiplying the thermal inertia by the temperature differential and a characteristic volume. For most materials, the volume specific heat is a temperature dependent property.

$$
q=\rho c_{p} V \frac{d T}{d \theta}=\rho c_{p} A_{n} I \frac{d T}{d \theta}
$$

Emitted Radiation

The heat transfer due to emitted radiation is described by a product of the Stefan-Boltzman constant, the surface characteristic of emittance, a surface area, and the fourth power of the absolute temperature. The 
emittance is the only factor over which there is a possibility of experimental control and is known to vary with temperature and surface conditions such as degree of roughness, oxidation, contamination, etc. The equation may be written:

$$
q=\varepsilon \sigma A_{S} T^{4} .
$$

Absorbed Radiation

The energy absorption rate at a surface is the product of the surface absorptance, the surface area, and the incident flux. The absorptance depends on the same factors as does the emittance and in addition on the spectral characteristics of the incident radiation. For this latter reason, it is advantageous to separate the radiant energy into parts identified by source.

One source of incident radiation is that being emitted from another portion of the system itself. This flux depends on the geometry of the system and on the distribution of the energy leaving the "viewed" surface. This distribution of energy leaving the "viewed" surface in turn depends upon the product of the Stefan-Boltzman constant, the emittance, the area and the fourth power of the absolute temperature of that surface.

As an equation, the heat transfer from surface $j$ absorbed at surface i may be written:

$$
q_{j i}=\alpha_{i j} \varphi_{j i}^{A}: S
$$


where $\alpha_{i j}$ is the absorptance of surface $i$ with regard to radiation from surface $j$ and $\varphi_{j i}$ is the energy flux leaving surface $j$ and arriving at surface $i$.

The radiant energy absorbed by surface $i$ which arrives from other sources may likewise be described by a number of flux terms with subscripts indicating their sources; that is,

$$
q_{k i}=\alpha_{i k} \varphi_{k i} A_{s}, \text { etco. }
$$

In the space simulation chamber used in the experimental work, the only radiation arriving from external sources was from the surrounding walls which were held at liquid nitrogen temperature, approximately $-300^{\circ} \mathrm{F}$ and which were painted with a special paint of high and uniform emittance.

Formation of the Dimensionless

\section{Similarity Parameters}

It is obvious from the previous sections that the thermal behavior of the system is determined by a relatively large number of dimensional factors. The application of reasonable restraints to some of these factors made the solution of the problem of thermal modeling easier to obtain. The implications of these restriction will be discussed in a later section. The first restriction was that the material be homogeneous and isotropic. The 
second was an assumption that there be perfect geometric similarity between prototype and model. Third, to eliminate the influence of spectral and angular distribution on the emitted and absorbed radiation, it was assumed that the prototype and model had the same uniform and constant surface characteristics.

For the formation of the similarity parameters, it was recognized that thermal similitude between prototype and model required that heat transfer and internal energy changes be proportional in prototype and model. The dimensionless groups, or pi groups, were formed from the heat transfer groups by normalizing with respect to the heat transfer by solid conduction.

The transfer equations previously discussed are listed as follows for the region i, a region of uniform temperature:

$$
\begin{aligned}
& \text { Solid conduction } \\
& q=k A_{n} \frac{d T}{d I} \\
& \text { Internal generation } \\
& q=q^{\prime \prime \prime} V=q^{\prime \prime \prime} A_{n} I \\
& \text { Internal energy changes } \\
& q=\rho c_{p} V \frac{d T}{d \theta}=\rho c_{p} A_{n} L \frac{d T}{d \theta} \\
& q=\varepsilon \sigma A_{s} T^{4} \\
& q_{j i}=\alpha_{i j} \varphi_{j i} A_{S} \\
& q_{k i}=\alpha_{i k} \varphi_{k i} A_{S} \text {, etc. }
\end{aligned}
$$

Normalizing the se equations with respect to the solid conduction heat transfer equation results in the following $\pi$ groups: 


$$
\begin{aligned}
& \pi_{I}=\frac{q^{\prime \prime I}}{k \frac{d T}{d I}} \\
& \pi_{2}=\frac{\varepsilon \sigma A_{S} T^{4}}{k A_{m} d T} \\
& \pi_{3}=\frac{\rho c_{p} L \frac{d T}{d \theta}}{k \frac{d T}{d I}} \\
& \pi_{4}=\frac{\alpha_{i j} I^{\varphi} j i I^{A} S}{k A_{i I} \frac{d T}{d I}} \\
& \pi_{5}=\frac{\alpha_{i k^{\varphi}}{ }^{k_{i}{ }^{A}} S}{k A_{i n} \frac{d T}{d I}} \text {, etc。 }
\end{aligned}
$$

It should be noted that the first group may be altered by recognizing that it is dimensionally consistent to write $q " \prime A_{n} I=q^{\prime \prime} A_{n}=q$, to obtain groups containing the heat flux and the heat transfer rate, respectively。 These are not independent groups.

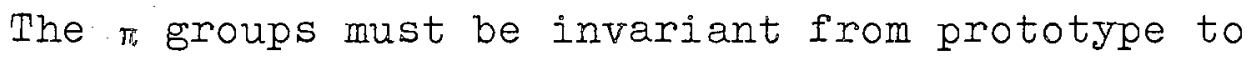
model. Equating the respective model and prototype groups and rearranging terms, letting the subscript $p$ quantities and their subscript $m$ counterparts represent the prototype and model, respectively, there results $a$. more usable form for the similarity paraters. 


$$
\begin{aligned}
& \frac{q^{\prime \prime \prime} m}{q^{\prime \prime \prime}}=\left(\frac{k \frac{d T}{d L}}{L}\right)_{m}\left(\frac{I}{k \frac{d T}{d I}}\right)_{p} \\
& \frac{q^{\prime \prime}}{q_{p}^{\prime \prime}}=\frac{\left(k \frac{d T}{d L}\right)_{m}}{\left(k \frac{d T}{d I}\right)_{p}}
\end{aligned}
$$

$$
\frac{q_{m}}{q_{p}}=\frac{\left(k A_{n} \frac{d T}{d \tau}\right)_{m}}{\left(k A_{n} \frac{d T}{d \tau}\right)_{p}}
$$

$$
\frac{T_{m}}{T_{p}}=\left(\frac{k A_{n} \frac{d T}{d I}}{\varepsilon \sigma A_{s}}\right)_{m}^{\frac{d}{4}}\left(\frac{\varepsilon \sigma A_{S}}{k A_{n} \frac{d T}{d L}}\right)_{p}^{\frac{1}{k}}
$$

$$
\frac{\left(\frac{\partial T}{d \theta}\right)_{m}}{\left(\frac{d T}{d \theta}\right)_{p}}=\left(\frac{k \frac{d T}{d L}}{\rho c_{p} I}\right)_{m}\left(\frac{\rho \varepsilon_{p} L}{k \frac{d T}{d I}}\right)_{p}
$$

$$
\frac{\left(\frac{d T}{d L}\right)_{m}}{\left(\frac{d T}{d L}\right)_{p}}=\left(\frac{\alpha_{i j} j_{j i^{A}} s}{k A_{n}}\right)_{m}\left(\frac{k A_{n}}{\alpha_{i j} j^{A}{ }^{A} s}\right)_{p}
$$

$$
=\left(\frac{\alpha_{i k^{\varphi} i^{A} s}}{k A_{n}}\right)_{m}\left(\frac{k A_{n}}{\alpha_{i k}{ }^{\varphi} k i^{A}}\right)_{p} \text {, etc。 }
$$

It is now appropriate to state that the emitting and absorbing surfaces of all models and prototypes, as well as the surrounding walls of the test chamber were painted with a flat black paint. The paint used was "velvet coating 101-C10," a product of Minnesota Mining and Manufacturing Company, which has been shown to have high and uniform values for emittance and absorptance (4). In 
view of this fact, it was assumed that the emittance and absorptance of the model were equal in value to the respective emittance and absorptance of the prototype. Further, the models were of such a chape that they could not "see" themselves, which eliminates Equation (2-6) from consideration. It is also reasonable to assume that the only incident flux, $\varphi_{k i}$, from the surrounding walls would be equal for both model and prototype.

Equations (2-7) and (2-4) may be written as:

$$
\begin{aligned}
& \frac{\left(\frac{d T}{d I}\right)_{m}}{\left(\frac{d T}{d I}\right)_{p}}=\left(\frac{A_{S}}{k A_{n}}\right)_{m}\left(\frac{k A_{n}}{A_{S}}\right)_{p} \\
& \frac{\left(\frac{d T}{d I}\right)_{m}}{\left(\frac{d T}{d I}\right)_{p}}=\left(\frac{A_{S} T^{4}}{k A_{n}}\right)_{m}\left(\frac{k A_{n}}{A_{S} T^{4}}\right)_{p}
\end{aligned}
$$

and from these equations there is obtained $T_{m}=T_{p}$ at homologous locations.

By considering plots of model and prototype temperatures versus dimensionless lengths; $i \circ e .,\left(I / I_{\max }\right)_{m}$ and $\left(L / L_{\text {max }}\right)_{p}$. it becomes evident that one curve will represent both model and prototype temperatures. The model/ prototype ratio of temperature gradients may then be expressed as:

$$
\frac{\left(\frac{d T}{d I}\right)_{m}}{\left(\frac{d T}{d L}\right)_{p}}=\frac{\left(I_{\text {max }}\right)_{p}}{\left(L_{\text {max }}\right)_{m}}=\frac{I_{p}}{I_{m}} .
$$

By substitution of Equation (2-10) into Equation (2-8), there is obtained 


$$
\frac{k_{m}}{k_{p}}=\left(\frac{I A_{s}}{A_{n}}\right)_{m}\left(\frac{A_{n}}{I A_{S}}\right)_{p} \text {. }
$$

Further, by substitution of Equations (2-10) and (2-11) into Equation (2-5), the following expression results:

$$
\frac{\left(\frac{d T}{d \theta}\right)_{m}}{\left(\frac{d T}{d \theta}\right)_{p}}=\frac{\left(\rho c_{p}\right)_{p}}{\left(\rho c_{p}\right)_{m}}\left(\frac{A_{s}}{I A}\right)_{m}\left(\frac{I A_{n}}{A_{S}}\right)_{p} \cdot
$$

Since $\mathbb{T}_{m}=\mathbb{T}_{p}$ at homologous times, by using an argument similar to that used to obtain Equation (2-10), it follows that the model/prototype ratio of temperature change rate is equal to the the inverse of the model/ prototype time scaling ratio。

$$
\frac{\left(\frac{\mathrm{dT}}{\mathrm{d \theta}}\right)_{m}}{\left(\frac{\mathrm{dT}}{\mathrm{d \theta}}\right)_{\mathrm{p}}}=\frac{\Delta \theta_{\mathrm{p}}}{\Delta \theta_{m}}
$$

Defining $\theta_{0}=0$ so that $\Delta \theta=\theta$, there results:

$$
\frac{\theta_{m}}{\theta_{p}}=\frac{\left(\rho C_{p}\right)_{m}}{\left(\rho C_{p}\right)_{p}}\left(\frac{I A}{A_{S}}\right)_{m}\left(\frac{A_{S}}{I A_{n}}\right)_{p}
$$

Further, substituting Equations $(2-10)$ and (2-11) into Equations $(2-1),(2-2),(2-3)$, there was obtained the following form for the similarity parameters:

$$
\begin{aligned}
& \frac{q^{\prime \prime \prime}}{q^{m}}=\left(\frac{A_{S}}{I A_{n}}\right)_{m}\left(\frac{I A_{n}}{A_{S}}\right)_{p} \\
& \frac{q^{\prime \prime}}{q_{p}^{\prime \prime}}=\left(\frac{A_{S}}{A_{n}}\right)_{m}\left(\frac{A_{n}}{A_{S}}\right)_{p}
\end{aligned}
$$




$$
\begin{aligned}
& \frac{q_{m}}{q_{p}}=\frac{\left(A_{S}\right)^{m}}{\left(A_{S}\right)_{p}} \\
& \frac{T_{m}}{T_{p}}=1 \\
& \frac{\theta_{m}}{\theta_{p}}=\frac{\left(P_{c}\right)_{m}}{\left(\rho_{c}\right)_{p}}\left(\frac{I A_{n}}{A_{s}}\right)_{m}\left(\frac{A_{s}}{I A_{n}}\right)_{p} \\
& \frac{k_{m}}{k_{p}}=\left(\frac{I A_{S}}{A_{n}}\right)_{m}\left(\frac{A_{n}}{I A_{s}}\right)_{p}
\end{aligned}
$$

The shapes used in the experimental work were solid cylinn ders with $A_{n}=\pi R^{2}, A_{S}=2 \pi R L$. Making these substitutions, there results an alternate form for the similarity parameters.

$$
\begin{aligned}
\frac{q^{\prime \prime \prime}}{q^{\prime \prime}} & =\frac{R_{p}}{R_{m}} \\
\frac{q_{m}^{\prime \prime}}{q_{p}^{\prime \prime}} & =\left(\frac{L}{R}\right)_{m}\left(\frac{R}{I}\right)_{p} \\
\frac{q_{m}}{q_{p}} & =\frac{(R L)_{m}}{(R I)_{p}} \\
\frac{T_{m}}{T_{p}} & =I \\
\frac{\theta_{m}}{\theta_{p}} & =\frac{\left(P c_{p} R\right)_{m}}{\left(\rho_{c} R\right)_{p}}
\end{aligned}
$$




$$
\frac{\mathrm{k}_{\mathrm{m}}}{\mathrm{k}_{\mathrm{p}}}=\left(\frac{\mathrm{I}^{2}}{\mathrm{R}}\right)_{\mathrm{m}}\left(\frac{\mathrm{R}}{\mathrm{I}^{2}}\right)_{\mathrm{p}}
$$

An Alternate Derivation of the

Similarity Parameters

Previous authors have used a method similar to that used in the preceding section but started with different heat transfer equations for solid conduction and internal energy changes. Using the equations

$$
q=\frac{k A_{n} T}{L}
$$

for solid conduction and

$$
q=\frac{\rho c_{p} V T}{\theta}=\frac{\rho c_{p} A_{n} L T}{\theta}
$$

for the internal energy changes and proceeding as in the previous section, with the same assumptions, there results the following set of similarity parameters for a cylindrical shaped prototype and its model. The assumption that the ratios $\mathrm{T} / \mathrm{L}$ and $\mathrm{T} / \theta$ may represent derivatives is discussed in a later section with other assumptions.

$$
\begin{aligned}
\frac{q^{\prime \prime \prime}}{q^{\prime \prime \prime}} & =\left(\frac{k T}{I^{2}}\right)_{m}\left(\frac{L^{2}}{k T}\right)_{p} \\
\frac{q^{\prime \prime}}{q_{p}^{\prime \prime}} & =\left(\frac{k T}{L}\right)_{m}\left(\frac{I}{k T}\right)_{p} \\
\frac{q_{m}}{q_{p}} & =\left(\frac{R^{2} k T}{L}\right)_{m}\left(\frac{L}{R^{2} k T}\right)_{p}
\end{aligned}
$$




$$
\begin{aligned}
& \frac{\theta_{m}}{\theta_{p}}=\left(\frac{\rho c_{p}^{I^{2}}}{k}\right)_{m}\left(\frac{k}{\rho c_{p}^{I^{2}}}\right)_{p} \\
& \frac{T_{m}}{T_{p}}=\left(\frac{k R}{I^{2}}\right)_{m}^{1 / 3}\left(\frac{I^{2}}{k \bar{R}}\right)_{p}^{1 / 3} \\
& \frac{T_{m}}{T_{p}}=\left(\frac{I^{2}}{k R}\right)_{m}\left(\frac{k R}{I^{2}}\right)_{p}
\end{aligned}
$$

The last two equations require that $T_{m}=T_{p}$. The last equation, obtained by considering radiant energy transfer from one surface of the system to another, has been neglected by previous authors. This permits modeling without the temperatures of model and prototype being equal at homologous locations. The use of the resulting parameters is valid only if different surfaces of the modeled system cannot "see" each other, and if the substitution of the $T / L$ and $T / \theta$ ratios, for the derivatives, is valid. By neglecting radiant energy interchange, Equation (2-3I) is omitted from consideration and the following equations result。

$$
\begin{aligned}
& \frac{q^{m p}}{q^{m p}}=\left[\left(\frac{k^{4} R}{L^{8}}\right)_{m}\left(\frac{I^{8}}{K^{4} R}\right)\right]^{l / 3} \\
& \frac{q^{\prime \prime}}{q_{p}^{\prime \prime}}=\left[\left(\frac{h^{4} R}{L^{5}}\right)_{m}\left(\frac{L^{5}}{k^{4} R}\right)_{p}\right]^{1 / 3} \\
& \frac{q_{m}}{q_{p}}=\left[\left(\frac{k^{4} R^{7}}{L^{5}}\right)_{m}\left(\frac{L^{5}}{k^{4} R^{7}}\right)_{p}\right]^{1 / 3} \\
& \frac{\theta_{m}}{\theta_{p}}=\left(\frac{\rho c_{p} I^{2}}{k}\right)_{m}\left(\frac{k}{\rho c_{p} I^{2}}\right)_{p}
\end{aligned}
$$




$$
\frac{\mathrm{T}_{\mathrm{m}}}{\mathrm{T}_{\mathrm{p}}}=\left[\left(\frac{\mathrm{kR}}{\mathrm{I}^{2}}\right)_{\mathrm{m}}\left(\frac{\mathrm{I}^{2}}{\mathrm{kR}}\right)_{\mathrm{p}}\right]^{1 / 3}
$$

Property Variations With Temperature

Most previous investigators have assumed at this point that thermal conductivity and specific heat did not vary with temperature. Chao (3) suggested that the temperature variation of these properties may be approximated by assuming a power law variation of the form:

$$
\begin{aligned}
k & =k_{o} T^{a} \quad\left(T={ }^{\circ} R\right) \\
c_{p} & =c_{p o} T^{b} \quad\left(T={ }^{o} R\right)
\end{aligned}
$$

Substituting these equations into the first set of similarity parameters derived, Equation (2-20) through (2-25), the following equations were obtained:

$$
\begin{aligned}
& \frac{q^{\prime \prime \prime} m}{q^{\prime \prime \prime}}=\frac{(R)_{p}}{(R)_{m}} \\
& \frac{q^{\prime \prime}}{q_{p}^{\prime \prime}}=\left(\frac{L}{\bar{R}}\right)_{m}\left(\frac{R}{\bar{L}}\right)_{p} \\
& \frac{q_{m}}{q_{p}}=\frac{(R L)_{m}}{(R L)_{p}} \\
& T_{m}=T_{p}=T \\
& \frac{{ }^{m}}{\theta_{p}}=\left[\frac{\left(\rho c_{\left.p 0^{R}\right)} m\right.}{\left(\rho_{\left.p o^{R}\right)_{p}}\right.}\right]\left[\mathrm{T}^{\left(b_{m}-b_{p}\right)}\right]
\end{aligned}
$$




$$
T^{\left(a_{m}-a_{p}\right)}=\left(\frac{L^{2}}{k_{0} R}\right)_{m}\left(\frac{k_{0}^{R}}{I^{2}}\right)_{p}
$$

From the second set of similarity parameters derived, Equations (2-32) through (2-36), the results of the substitutions were as follows:

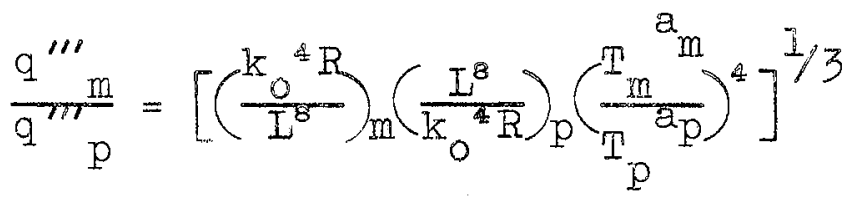

$$
\begin{aligned}
& \frac{q_{m}^{\prime \prime}}{q_{p}^{r}}=\left[\left(\frac{k_{0}{ }^{4} R}{I^{5}}\right)_{m}\left(\frac{L^{5}}{k_{0} R}\right)_{p}\left(\frac{T_{m}^{a_{m}}}{T_{p}{ }^{a} p}\right)^{1 / 3}\right. \\
& \frac{q_{m}}{q_{p}}=\left[\left(\frac{K_{0}^{4} R^{y}}{L^{5}}\right)_{m}\left(\frac{I^{5}}{k_{0}^{4} R^{7}}\right)_{p}\left(\frac{m^{m}}{T_{p}^{2} p}\right)^{4 / 3}\right]^{1 / 3} \\
& \frac{\theta_{m}}{\theta_{p}}=\left(\frac{p c_{p o} L^{2}}{k_{0}}\right)_{m}\left(\frac{k_{0}}{\rho_{p o} L^{2}}\right)_{p} \frac{T_{m}^{b_{m}}-a_{m}}{T_{p} b_{p}-a_{p}} \\
& \frac{T_{m}}{T_{p}}=\left[\left(\frac{k_{0} R}{I^{2}}\right)_{m}\left(\frac{I^{2}}{k_{0} R}\right)_{p}\left(\frac{T_{m}{ }^{a_{m}}}{T_{p} a_{p}}\right)\right]^{1 / 3}
\end{aligned}
$$

Since the parameters must not be functions of temperm ature, it is evident that Equations (2-37) through (2-47) are usable only if $a_{m}=a_{p}$ and $b_{m}=b_{p}$. It is unlikely that it would be possible to choose a model material to properly match the prototype material unless the same material were used for both model and prototype (i。e., $\left.a_{m}=a_{p}: b_{m}=b_{p}:\left(c_{p o}\right)_{m}=\left(c_{p o}\right)_{p}: i_{o m}=i_{o p}\right)$. This material preservation requirement permits Equation (2 -42 ) 
to be reduced to

$$
\frac{\mathrm{R}_{m}}{\mathrm{R}_{\mathrm{p}}}=\frac{\mathrm{I}_{\mathrm{m}}^{2}}{\mathrm{I}_{\mathrm{p}}^{2}}
$$

and Equations (2-37) through (2-4I) reduce to

$$
\begin{gathered}
\frac{q^{\prime \prime \prime} m}{q^{m}}=\frac{L_{p}^{2}}{L_{m}^{2}} \\
\frac{q^{\prime \prime}}{q_{p}^{\prime \prime}}=\frac{I_{p}}{L_{m}} \\
\frac{q_{m}}{q_{p}}=\frac{I_{m}^{3}}{L_{p}^{3}} \\
\frac{T_{m}}{T_{p}}=1 \\
\frac{\theta m}{\theta_{p}}=\frac{I_{m}^{2}}{L_{p}^{2}}
\end{gathered}
$$

The Equations (2-43) through $(2-47)$ xeduce to:

$$
\begin{aligned}
& \frac{q^{\prime \prime \prime}}{q^{m}}=\left[\left(\frac{R^{I+a}}{I^{8}}\right)\left(\frac{I^{8}}{R^{I+a}}\right)\right]^{\frac{I}{3-a}} \\
& \frac{q^{\prime \prime}}{q_{p}^{\prime \prime}}=\left[\left(\frac{R^{I+a}}{L^{5+a}}\right)_{m}\left(\frac{I^{5+a}}{R^{I+a}}\right)_{p}\right]^{\frac{I}{3-a}} \\
& \frac{q_{m}}{q_{p}}=\left[\left(\frac{R^{7-a}}{L^{5+a}}\right)_{m}\left(\frac{I^{5+a}}{R^{7-a}}\right)_{p}\right]^{\frac{1}{3-a}}
\end{aligned}
$$




$$
\begin{aligned}
& \frac{\theta_{m}}{\theta_{p}}=\left[\left(\frac{R^{b-a}}{L^{2 b-6}}\right)_{m}\left(\frac{L^{2 b-6}}{R^{b-a}}\right)_{p}\right]^{\frac{1}{3-a}} \\
& \frac{T_{m}}{T_{p}}=\left[\left(\frac{R}{I^{2}}\right)_{m}\left(\frac{I^{2}}{R}\right)_{p}\right]^{\frac{I}{3-a}} .
\end{aligned}
$$

\section{The Similarity Parameters}

Table I presents the results of the previous derivation of three sets of similarity parameters. The first set, derived by the author and referred to as Method 1, takes into account the changes of thermal conductivity and specific heat with temperature, and requires that model and prototype temperatures be equal. This method is the most restrictive of the three. Any model-prototype system which meets the dimensional requirements of this method will also meet the requirements of the other two methods.

The second set, derived by the author and referred to as Method 2, takes into account changes of thermal conductivity and specific heat with temperature, but does not require that model and prototype temperatures be equal. This method eliminates that restriction by assuming energy absorbed by the model and prototype, from the surrounding walls, may be neglected.

The third set of parameters, derived by previous authors, neglects changes in thermal conductivity and specific heat with temperature, and does not require that model and prototype temperatures be equal. This method 
also assumes energy absorbed by the model and prototype, from the surrounding walls, may be neglected.

All three methods assume that model and prototype are to be made of the same material. In order to simplify the equations, starred quantities will hereafter represent the model to prototype ratio of that parameter (i。e., $T^{*}=T_{m} / T_{p}, q^{*}=q_{m} / q_{p}$, etc。

\section{TABLE I \\ THE SIMIIARITY PARAMETERS}

Parameter Method 1 Method 2 Method 3

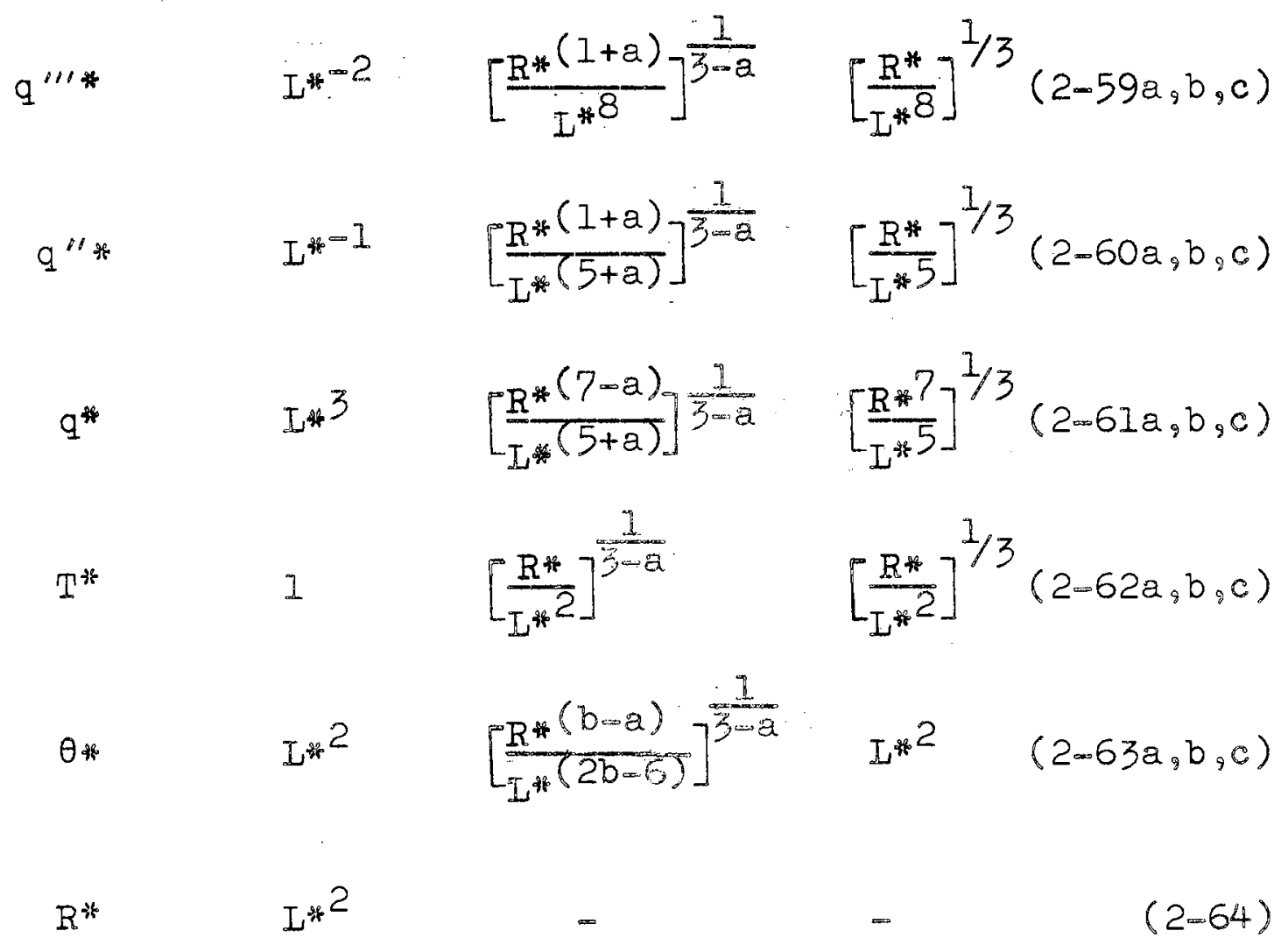


Application to Joined Materials

The previous section was concerned with modeling a single material prototype with a single material model. If the prototype and model are both made of two materials joined with a high conductivity joint, there must be continuity of temperature and heat transfer rate across that joint. The time ratio, $\theta^{*}$, must also be the same for both materials if proper modeling is to be achieved.

The Method 2 parameters, (2-59b) through (2-63b) of Table I will be used as a starting point in deriving the necessary scaling laws for modeling two joined materials. This method takes into account the changes of thermal conductivity and specific heat with temperature but does not, at this point, require model and prototype temperatures to be equal.

Assuming a prototype of two materials, indicated by subscripts 1 and 2 , is modeled with the same two materials, continuity of conduction heat transfer and flux require that:

$$
\begin{aligned}
& q^{\prime \prime} *=\left[\frac{R_{1} *\left(1+a_{1}\right)}{L_{1}^{*}\left(5+a_{1}\right)}\right]^{\frac{I}{3-a_{1}}}=\left[\frac{R_{2}^{*\left(1+a_{2}\right)}}{I_{2}\left(5+a_{2}\right)}\right]^{\frac{1}{3-a_{2}}} \\
& q^{*}=\left[\frac{R_{1}^{*}\left(7-a_{1}\right)}{I_{1} *\left(5+a_{1}\right)}\right]^{\frac{1}{3-a_{1}}}=\left[\frac{R_{2}^{*}\left(7-a_{2}\right)}{I_{2}^{*}\left(5+a_{2}\right)}\right]^{\frac{1}{3-a_{2}}}
\end{aligned}
$$


Dividing Equation (2-65) by (2-66) and collecting terms, the result is:

$$
\mathrm{R}_{1}^{*}=\mathrm{R}_{2}^{*}=\mathrm{R}^{*} \text { 。 }
$$

Combining Equation (2-65) with a similar equation for q"* " the result is:

$$
I_{1}^{*}=I_{2}^{* *}=I^{*}
$$

There must also be continuity of temperature across the joint, which may be expressed by

$$
\mathrm{T} *\left[\frac{\mathrm{R}_{1}^{*}}{\mathrm{~L}_{1}^{*}{ }^{2}}\right]^{\frac{1}{3-\mathrm{a}_{1}}}=\left[\frac{\mathrm{R}_{2}^{*}}{\mathrm{~L}_{2}{ }^{*}{ }^{\frac{1}{3-\mathrm{a}_{2}}}} .\right.
$$

Using previously obtained results, Equations (2-67) and $(2-68)$, there is obtained:

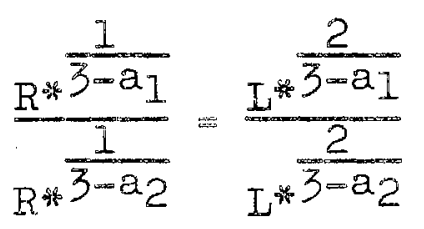

and by simplifying, the result is

$$
\begin{aligned}
\frac{a_{1}-a_{2}}{R^{*}\left(3-a_{1}\right)\left(3-a_{2}\right)} & =I^{*} \frac{2\left(a_{1}-a_{2}\right)}{\left(3-a_{1}\right)\left(3-a_{2}\right)} \\
R^{*} & =I^{*} .
\end{aligned}
$$

Substituting this result into the similarity parameters derived for Method 2 , Table I, there is obtained the exact results derived by Method 1, which requires equality of temperature between modeI and prototype. 
It would sometimes be convenient to scale according to the relationship $R^{*} \neq L^{* 2}$. If this is done, it is relatively easy to show that the results of Method 2 would require that $a_{1}=a_{2}$ and $b_{1}=b_{2}$, a requirement that would probably be quite difficult to fulfill. Of course, the assumption of no change in thermal conductivity and specific heat with temperature, Method 3, would satisfy this requirement (i.e., $a_{1}=a_{2}=0 ; b_{1}=b_{2}=0$ ).

\section{Verification of Results}

It should be noted again that the only method of proving the value of the dimensionless similarity parameters is to experimentally verify their correctness.

In order to accomplish this verification, cylindrical prototypes and models of various scaling ratios were constructed, some having only one material and some having two materials.

There was no internal energy generation within the model itself and the instrumentation provided no method of checking the heat flux ratio. Consequently, the Parameters (2-59) and (2-60) of Table I could not be verified. The single material prototype had models scaled such that $R^{*}=I^{* 2}$ and $R^{*}=L^{*}$ 。 The first of these satisfied Method 1 of Table I and the second al. lowed Method 2 to be compared to Method 3.

The two material prototype had models scaled such 
that $R^{*}=I^{* 2}$, which satisfies Method 1 of Table $I$.

For experimental purposes, the prototype energy input was arbitrarily selected and the required model energy input was calculated from model dimensions and thermal properties according to Parameter (2-61).

From the temperature and time data recorded for each model, homologous temperatures and times were calculated for the prototype using the Parameters (2-62) and (2-63). These calculated values were compared with measured values to determine the validity of the derived similarity parameters.

\section{Discussion of Assumptions}

The assumptions made in deriving the similarity parameters were:

1. Surface properties (emissivity, absorptivity) were the same for both model and prototype and did not vary with temperature.

2. Thermal properties (conductivity, specific heat) were constant or varied according to a power law variation.

3. There was perfect geometric similarity between model and prototype.

The first assumption was met by painting the models and prototypes with a flat black paint which has been shown to have a reproducible, uniform, and constant value 
for emissivity and absorptivity numerically equal to 0.97 (4).

The assumption that thermal conductivity and specific heat were either constant or varied according to a power law may be evaluated by taking specific examples. The two materials used in the experimental work were 2024-T4 aluminum, heated to $600^{\circ} \mathrm{F}$ for one hour and air cooled before use, and 316 stainless steel, heated to $2000^{\circ} \mathrm{F}$ for one hour and water quenched before use. Iucks and Deem (10) give the following values for thermal properties as a function of temperature.

TABLE II

THERMAL PROPERTIES OF MATERIALS

\begin{tabular}{|c|c|c|c|c|}
\hline $\begin{array}{c}\text { Temperature } \\
\left({ }^{\circ} \mathrm{F}\right)\end{array}$ & $c_{p}\left(\frac{B^{2024}}{I b m-\omega^{\circ} R}\right)$ & $\stackrel{\text { Aluminum }}{\left(\frac{B}{h r-f t^{-} R}\right)}$ & $e_{p}\left(\frac{B 16}{16 m-{ }^{\circ} R}\right)$ & $\begin{array}{l}\text { sis Stee } 1 \\
k\left(\frac{B}{h r-f t-o R}\right)\end{array}$ \\
\hline-100 & 0.176 & 95 & 0.094 & 6.9 \\
\hline 68 & 0.203 & 103 & 0.108 & 7.7 \\
\hline 200 & 0.217 & 107 & 0.116 & 8.3 \\
\hline 400 & 0.231 & 110 & 0.126 & 9.2 \\
\hline
\end{tabular}

A least square error fit was used to obtain a power law equation for these properties of the form 


$$
\begin{array}{ll}
k=k_{0} T^{2} & \left(360^{\circ} \mathrm{R} \leq \mathrm{T} \leq 860^{\circ} \mathrm{R}\right) \\
c_{p}=c_{p 0^{T^{b}}} & \left(360^{\circ} \mathrm{R} \leq \mathrm{T} \leq 860^{\circ} \mathrm{R}\right)
\end{array}
$$

Table III presents values of the equation constants obtained from the least square error fit. The table includes values of the standard deviation calculated for each set of constants for the particular temperature range covered by the original data.

TABIE III

\begin{tabular}{|c|c|c|c|c|c|c|}
\hline Meterolal. & $a$ & $k_{0}$ & $\begin{array}{l}\text { Standard } \\
\text { Deriation }\end{array}$ & $b$ & $a_{p o}$ & $\begin{array}{l}\text { Standard } \\
\text { Dewation }\end{array}$ \\
\hline $\begin{array}{l}2024 \\
\text { A.luminum }\end{array}$ & 0.1709 & 34.88 & 1.1 & 0.3146 & 0.0279 & 0.002 \\
\hline $\begin{array}{l}316 \\
\text { Stainless steel }\end{array}$ & 0.3284 & 0.9916 & 0.074 & 0.3366 & 0.0130 & .0 .0007 \\
\hline
\end{tabular}

THERMAI CONSTANTS

To consider a specific example of the effect of not taking the temperature variation of conductivity into account, suppose a 2024 aluminum prototype-model combination was scaled such that $R^{*}=I^{*}=0.3333$, with a measured model temperature of $750^{\circ} \mathrm{R}$. Equation (2-62b), which 
takes the property variation into account, predicts a prototype temperature of $509^{\circ} \mathrm{R}$, while Equation (2-62c), which neglects the property variation, predicts a prototype temperature of $520^{\circ} \mathrm{R}$, a difference of 11 degrees. It is evident that different results will be achieved by taking the property variation into account.

The third assumption of perfect geometric similarity does not affect the results since the shape chosen for the experimental work cannot" see" itselfo Perfect geometric similarity impiies the geometric shape factor for energy which leaves any surface $j$ and arrives at surface i is the same for model and prototype.

Another assumption, that the ratios $T / L$ and $T / \theta$ may be substituted for the derivatives aT/dL and $\mathrm{dT} / \mathrm{d} \theta$, has been consistently used by previous authors and is used with reservation by this writer in the derivation of the Methods 2 and 3 parameters. The substitution is not logically correct. However, the experimental results presented Iater indicate the Methods 2 and 3 parameters are satis factory for the geometric shape tested and the range of temperatures and temperature gradients which existed in these systems. The derivation of the Method 1 parameters does not make these substitutions and the consequence is that there is temperature preservation between model and prototype. Temperature preservation is an apparent necessity for proper thermal modeling。 


\section{CHAPTER III}

\section{A SURVEY OF THE IITERATURE}

The problem of thermal modeling as related to spacecraft applications was recognized in the literature as early as 1962. A comprehensive review of the literature, published in May, 1965 was authored by Vickers (1). The article discussed at length the general problems of thermal modeling, the reasons for improving the state-of-theart, and the advantages to be derived therefrom. Vickers stated that there were two methods of modeling: "temperature preservation," where the model and prototype abso-. lute temperatures were equal, and "material preservation" where model and prototype were constructed of the same material. He further concluded that the two methods were mutually exclusive. The statement was made on the assumption of perfect geometric similarity between model and prototype and the statement is true under that assumption. The possibility of developing a method of having both temperature and material preservation was an objective of this dissertation. Vickers concludes that "the laws controlling thermal modeling of a spacecraft are well understood" and that experimental work on steady state modeling 
has been proven possible. Transient modeling problems are more severe, but "some work to be published offers hope for the future."

Jones (2) used the differential equations which described the thermal behavior of a spacecraft to derive the similarity parameters of thermal modeling. He compared his resulting similarity parameters with those of other investigators, principally Vickers (5), to show that the results were the same.

Chao and Wedekind (3) provided the most general derivation of the similarity parameters. A great deal of their work was concerned with solar simulation and the proper design of models which have incident solar radiation and which could "see" themselves. They introduced the concept of using a power law function of temperature for specific heat and thermal conductivity and also discussed the possibility of the model not being geometricalIy similar to the prototype. In the discussion of the "material preservation" technique of modeling two materials joined together, the requirement was imposed that the exponents for the power law functions of conductivity and specific heat, for the first material, must be equal to the corresponding exponents for the second material. An objective of this dissertation was to investigate a method of geometric scaling where this requirement could be omitted. 
The problem of thermal modeling under steady-state conditions was examined both analytically and experimentally by Fowle and Gabron (4). A derivation of the thermal modeling parameters was presented using the intuitive technique. Very careful and detailed experimental work was presented for modeling under steady-state conditions for both "temperature preservation" and "material preservation" techniques. No solar simulation was used. Constant thermal properties and perfect geometric similarity were assumed.

In 1963 Vickers (5) discussed again the techniques which could be evolved from the basic laws of thermalscale modeling of spacecraft. He reported that:

All but two of these techniques may be rejected at once, since they require conditions which are very difficult to achieve in practice. A comparison was drawn between the two remaining techniques, the technique of preserving temperature from prototype to model and of preserving materials from prototype to model.

The equations presented for the similarity parameters by Vickers in this article agreed with those developed by Jones (2), Fowle and Gabron (4), and earlier writers. The parameters assume perfect geometric similarity and constant thermal properties and correspond with this author's similarity parameters of Method 3, presented in Table I, with a geometric scaling of $R^{*}=L^{*}$ 。

In January, 1965, Gabron and Johnson (6), of A. D。 Little, Inc., submitted a report to the Jet Propulsion 
Laboratory describing their work on thermal modeling of the Mariner Mars 64 spacecraft. The objective of the research was to design, fabricate, and test a 0.43 scale model of the spacecraft under steady-state thermal conditions, with no solar radiation, based on the "temperature preservation" technique. Geometric similarity was main-n tained. It was concluded that "temperatures within a complex spacecraft structure, typical of the Mariner vehicle, can be predicted by use of 'temperature preservation' thermal-scale modeling techniques to an accuracy useful for the verification of thermal design concepts."

Rolling (7) presented results of thermal model studies on full-scale, half-scale, and quarter-scale thermal models. The half-scale model was designed on the basis of the "material preservation" technique and the quarterscale model designed on the basis of the "temperature preservation" technique. Simulated solar radiation was used and both steady-state and transient thermal conditions were imposed on the prototype and models. Perfect geometric similarity was not maintained where it could be argued that a departure from geometric similarity would. not appreciably affect the over-all thermal behavior. Thermal properties were assumed constant.

The design of the models was limited to using standard size plates and tubes and ordinary construction tech niques. Thus, the model dimensions were not exactly as 
required by the similarity parameters. The results indicated that this technique may be used to predict prototype temperatures to within $15^{\circ} \mathrm{F}$.

Gabron and Johnson (8) presented steady-state data from a prototype and its model, constructed at approximately one-half scale using the "temperature preservation" technique and preserving geometric similarity. The prototype was the actual Mariner IV spacecraft, and data from the prototype were those telemetered to earth from Mariner IV during the 98th and 180th flight day after launch, and for the "Mars playback" mode in which the internal power dissipation in the spacecraft was significantly reduced. For the three tests, temperatures were compared at 20 homologous locations in the model and prototype, with 48 per cent corresponding within $10^{\circ} \mathrm{F}$ and 85 per cent within $25^{\circ} \mathrm{F}$. The conclusions reached were:

The results of this program have shown that thermal-scale modeling can be successfully applied to the prediction of flight temperaw tures of a complex spacecraft. Temperature predictions made from measurements with a small scale thermal model in an environmental chamber are sufficiently accurate to presently warrant the use of the se techniques in preliminary design and development of large, complex spacecraft.

A recent paper by Adkins (9) introduced a method of geometric scaling which made thermal modeling possible while preserving both material and temperature. The equation describing the geometric relationship between system wall thickness and length was the same as the equation 
derived by this writer for the relationship between system radius and length; namely, $R^{*}=L^{* 2}$. Constant thermal properties were assumed and no simulated solar radiation was used.

Adkins worked with a hollow cylinder and sphere, heated by radiation from an adjacent flat plate heater, to which the electrical input was changed to obtain transient conditions. The radius and length of the cylinder were both scaled according to $\mathrm{R}^{*}=\mathrm{I}^{*}=0.5$, while the wall thickness $(t)$ was scaled accorajng to $t^{*}=I^{* 2}=0.25$. The radius of the sphere was scaled according to $R^{*}=0.5$ and the wall thickness as $t^{*}=0.25$. Adkjns called this the "thin shell approximation." No attempt was made to apply these scaling relations to joined materials with different thermal properties.

Experimental results were presented for "average" cylinder temperature and sphere temperatures. At homolow gous locations and times, the model and prototype temperm atures agreed to within about $20^{\circ} \mathrm{F}$.

In January, 1966, Shih (13) presented a discussion of thermal modeling which included the presentation of some of the sane similarity parameters derived by this writer. He took into account changes of thermal conductivity and specific heat with temperature and included the geometric relationship $\mathrm{R}^{*}=\mathrm{I}^{* 2}$ for preserving both material and temperature in model and prototype. No 
experimental work was presented or planned, nor was there any reference to joined materials with different thermal properties. 


\section{CHAPTER IV}

\section{EXPERIMENTAI PROGAM}

Model Design and Construction

There were two phases of the experimental program. The first phase consisted of tests on a prototype and four models constructed of 2024 aluminum, heated to $600^{\circ} \mathrm{F}$ for one hour and air cooled before using. Two of the models were constructed such that $R^{*}=I^{*}$ to check the validity and compare the results of the Methods 2 and 3 similarity parameters. Two of the models were constructed such that $\mathrm{R}^{*}=\mathrm{I}^{* 2}$, to check the validity of the Method 1 parameters. It would be appropriate at this point to restate the requirements of the three methods. Method 1 required model and prototype temperatures to be equal at homologous Iocations and times and dimensional scaling such that $R^{*}=$ $L^{* 2}$. The method took into account changes of thermal conductivity and specific heat with temperature.

Method 2 required no particular geometric relation between $R^{*}$ and $L^{*}$ and so did not require $T^{*}=I$. ThermaI conductivity and specific heat variations were considered. Radiant energy absorbed by the model or prototype from other portions of themselves was neglected. 
Method 3 required no particular geometric scaling and, thus, did not require $T^{*}=1$. Thermal conductivity and specific heat were assumed constant and radiant energy absorbed by the model or prototype from other portions of themselves was neglected.

The second phase of the experimental program consisted of tests on a prototype and two models, each having two materials, 2024 aluminum heat treated as were the first phase materials, and 316 stainless steel, heated to $2000^{\circ} \mathrm{F}$ for one hour and water quenched before using. The models were scaled such that $R^{*}=I^{* 2}$, as required by the Method 1 parameters of Table I. The two materials were soldered together with "All-State $509 "$ solder to achieve a high conductivity joint.

Tables IV and $V$ give the actual dimensions of the prototypes and models for the two phases of the experimental program。

The energy input to the prototypes and models was by electrical resistance heating. One end of the system was dipped in an air-drying epoxy cement, wound with an appropriate number of turns of 30-gage resistance wire, and dipped again the epoxy cement. Two copper leads, enameled and cotton wrapped, were attached to each end of the heater wire, one for electrical potential measurement and one for carrying current. The heater section was wrapped with ten layers of "NRC-2", an aluminized mylar. "NRC-2" 
TABLE IV

PROTOTYPE AND MODEL DIMENSIONS, SINGLE MATERIAL

HTR.

\begin{tabular}{|c|c|c|c|c|c|}
\hline $\begin{array}{l}\text { Model } \\
\text { No. }\end{array}$ & $\begin{array}{l}\text { Length } \\
L(\text { in. })\end{array}$ & $\begin{array}{l}\text { Heater Length } \\
L_{H}\left(I_{*}\right)\end{array}$ & $\begin{array}{c}\text { Dlameter } \\
\text { D (1n.) }\end{array}$ & $\mathrm{L}^{*}$ & $\mathrm{R}^{*}$ \\
\hline Proto. 1 & 17.242 & 2.25 & 2.001 & - & - \\
\hline $1-1$ & 8.637 & 1.13 & 1.001 & 0.501 & 0.500 \\
\hline $1-2$ & 5.714 & 0.75 & 0.661 & 0.331 & 0.331 \\
\hline $1-3$ & 8.641 & 1.13 & 0.498 & 0.501 & 0.249 \\
\hline $1-4$ & 6.120 & 0.80 & 0.249 & 0.355 & 0.125 \\
\hline
\end{tabular}

TABLE V

PROTOTYPE AND MODEL DIMENSIONS, TWO MATERIALS

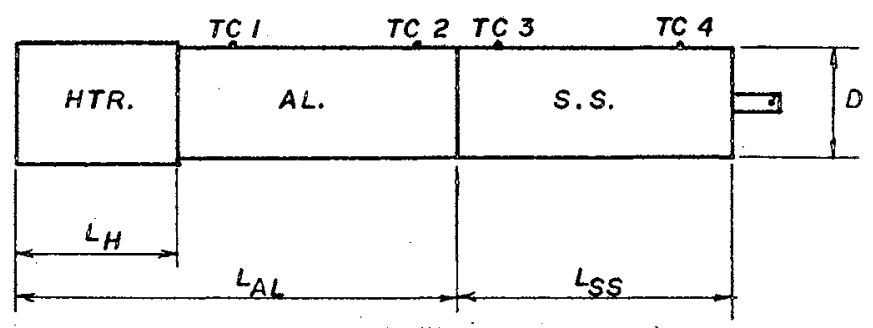

\begin{tabular}{|c|c|c|c|c|c|c|c|}
\hline $\begin{array}{l}\text { Mode1 } \\
\text { No. }\end{array}$ & $\begin{array}{l}\text { A1. Length } \\
\mathrm{L}_{\mathrm{AL}}(\mathbf{1 n} .)\end{array}$ & $\begin{array}{l}\text { Her. Length } \\
\mathrm{L}_{\mathrm{H}} \text { (in.) }\end{array}$ & $\begin{array}{l}\text { S.s. Length } \\
\mathrm{I}_{\mathrm{SS}}(1 \mathrm{n} .)\end{array}$ & $\begin{array}{l}\text { Al. Dia. } \\
D(\text { in. })\end{array}$ & $\begin{array}{l}\text { S.s. Dia. } \\
\text { D (1n.) }\end{array}$ & $\mathrm{L}^{*}$ & $\mathrm{R}^{*}$ \\
\hline Proto. 2 & 9.750 & 2.25 & 7.440 & 2.002 & 1.995 & - & - \\
\hline $2-1$ & 4.871 & $1: 13$ & 3.735 & 0.497 & 0.499 & 0.501 & 0.249 \\
\hline $2-2$ & 3.456 & 0.80 & 2.657 & 0.252 & 0.248 & 0.356 & 0.125 \\
\hline
\end{tabular}


is a product of National Research Corporation. The heater and potential leads were brought out between the fifth and sixth layers of insulation.

The heater section and the enclosing insulation were appropriately scaled in length so that the values of $I^{*}$ in Tables IV and $V$ were maintained. The heater lengths are given in Table IV and $V$. The heaters were on the aluminum end of the two material systems.

The models were supported vertically by a single polished constantan wire, attached to the end of the model opposite the heater. The wire was very long relative to the diameter to minimize conduction losses. The prototypes were supported horizontally by a polished constantan wire on each end. The heater and support wire diameters are given in Table VI。

The thermocouples used were all copper-constantan, polished for about twelve inches from the point where they left the system. Wire gages used are given in Table VI. Three thermocouples were attached to each of the single material systems, located at 10 per cent, 60 per cent, and 90 per cent of the exposed system length, measured from the end away from the heater.

Four thermocouples were attached to each of the two material systems, located at 10 per cent, 43.3 per cent, 56.7 per cent, and 90 per cent of the exposed system length, measured from the end away from the heater. The 
TABIE VI

HEATER, SUPPORT, AND THERMOCOUPIE WIRE GAGES

\begin{tabular}{lcccc}
\hline Model No. & $\begin{array}{c}\text { Heater Wire Gage } \\
\text { Potential }\end{array}$ & $\begin{array}{c}\text { Support Wire Gage } \\
\text { Curent }\end{array}$ & $\begin{array}{c}\text { Thermocouple Wire Gage } \\
\text { (copper-constantan) }\end{array}$ \\
\hline Proto. I and 2 & 30 & 24 & 24 & 24 \\
$1-1$ & 30 & 24 & 30 & 30 \\
$1-2$ & 30 & 24 & 30 & 38 \\
$1-3$ and $2-1$ & 30 & 30 & 30 & 38 \\
$1-4$ and $2-2$ & 30 & 30 & 30 & 38 \\
\hline
\end{tabular}


thermocouple junction was formed by soldering the wires together and was then hammered to fit the curvature of the system surface. A spot of high vacuum grease was placed between the metal and the thermocouple junction to provide good thermal contact. The lead wires were wrapped circumferentially $90^{\circ}$ away from the junction to prevent thermal conduction away from the junction. The lead wires were kept from electrical contact with the system by a layer of one-fourth mil mylar between the wire and the metal system. The thermocouple junction and lead wires were kept in place by a light covering of epoxy cement.

All of the system except the heater section was spray painted with flat black paint to a mean thickness of 0.003 inches.

Support Equipment

The space simulation chamber was a horizontal cylinder four feet long and two feet in diameter, constructed of stainless steel. Instrumentation feed-throughs for copper-constantan thermocouples, for heater current; and for liquid nitrogen were available. Pumping was provided by a rotary mechanical pump in series with a six inch oil diffusion pump. Inside the main chamber was a twenty-six inch long, twenty inch diameter inner chamber (liner) constructed of copper and spiral wrapped with one-quarter inch diameter copper tubing which carried liquid nitrogen. 
Conduction from the liner to the outer chamber walls was minimized by supporting the liner on three legs which contacted the outer chamber walls only along a short, sharp edge. One end of the liner was covered with an optically tight baffle which had attached liquid nitrogen cooling coils. The other end was a solid copper removable plate with a six inch diameter hole centrally located and was cooled by conduction from the liner walls. During all tests, the chamber was maintained at a pressure below $1 \times 10^{-6}$ torr ( $\mathrm{mm}$ of $\mathrm{Hg}$. ), resulting in a molecular mean free path of at least 50 meters. The liner wall was maintained at a measured temperature of $-300^{\circ} \mathrm{F}$ with liquid nitrogen. Other tests have shown that the removable liner end plate temperature was below $-275^{\circ} \mathrm{F}$ 。

The thermocouple output was indicated by a digital read-out, self-balancing potentiometer having a resolution of \pm 0.001 millivolts and a reproducible accuracy of better than \pm 0.005 millivolts. The instrument was calibrated with a Leeds and Northrup Model 8686 portable potentiometer. The value of \pm 0.005 miliivolts represented approximately \pm 0.25 degrees in the temperature range of the experimental work. The thermocouple cold junction was maintained at $32^{\circ} \mathrm{F}$ with an ice bath.

Before each test, the thermal model with attached thermocouples was exposed to vacuum conditions at ambient temperature for several hours. At equilibrium conditions 
the output of the three or four thermocouples attached to the model were equal within \pm 0.002 millivolts. Under these conditions, it was reasonable to assume that temperatures were measured to an accuracy of at least \pm 1.0 degree.

Current input to the heater was determined by measuring the millivolt drop across a calibrated shunt in series with the heater, with the same self balancing potentiometer which was used for therrocouple output. The shunt resistance was measured to within \pm 0.1 per cent with a Kelvin bridge. The potential drop across the heater was measured with a digital voltmeter having four digit capacity and calibrated to \pm 1 digit accuracy. Separate leads were provided to the heater for current and potential measurement. The input impedance of the digital voltmeter was greater than one megohm.

The D-C power supply used to provide heater power was voltage regulated to within \pm 3 millivolts and could be hand controlled to within \pm 1 millivolt during test runs. The combination of these elements provided a power measurement accuracy of $t 0.5$ per cent or better.

Time measurement was accomplished by observing the sweep second hand of a wrist watch. The procedure could have a measurement error of $\$ 5$ seconds. This error, occurring during the test of the smallest model, represented less than 1 per cent of the time required for 63 
per cent of the total temperature change to take place.

\section{Experimental Procedure}

The thermal system was installed in the test chamber, pump-down was accomplished and the thermocouples were checked for equality of output after several hours of pressure and thermal equilibrium. Iiquid nitrogen flow was started, with a cool down time of approximately six hours. The copper tubing around the liner was maintained full of liquid nitrogen by a liquid level control system. The model was protected from temperature extremes by changing the heater input during the cool awn period. The input to the model heater was set to the desired value and temperatures recorded until thermal equilibrium was established. Thermal equilibrium implied temperature change rates of less than 0.5 degrees per hour. At this point, after recording all necessary data, the power input to the heater was charged to a higher selected value and temperatures and times were recorded at intervals until a new thermal equilibrium was reached. 


\section{CHAPTER V}

\section{EXPERIMENTAL RESULTS}

As outlined in the previous chapter, the experimental program consisted of two phases: one phase for a single material system and one phase for a two material system. Values for the similarity parameters are presented in Tables VII and VIII. These values were calculated from the relationships for the similarity parameters from Table I, the model and prototype dimensions from Tables IV and $V$, and the property constants from Table III. Although models $1-3$ and $1-4$ were intended to be scaled such that $\mathrm{R}^{*}=\mathrm{L}^{* 2}$, slight variations in dimensions were unavoidable。 Consequently, the equations of Method 2 were used to calculate the parameter values for these models since exact dimensional requirements of Method 1 were not fulfilled.

$$
\text { Steady-State Results }
$$

The energy input to the prototype was arbitrarily selected and a correspondingly scaled input was used for each model according to the value of $q^{*}$ from Tables VII and VIII. 
TABLE VII

CALCULATED VALUES OF SIMILARITY PARAMETERS

SINGLE MATERIAL

\begin{tabular}{cccccccc}
\hline Model No. & q* & Method 2 & T* & T* & $q^{*}$ & $\theta *$ & T*thod \\
\hline $1-1$ & 0.6647 & 0.2599 & 1.277 & 0.6288 & 0.2509 & 1.259 \\
$1-2$ & 0.5200 & 0.1162 & 1.476 & 0.4758 & 0.1098 & 1.444 \\
$1-3$ & 0.1231 & 0.2510 & 0.997 & 0.1232 & 0.2512 & 0.997 \\
$1-4$ & 0.0435 & 0.1259 & 0.996 & 0.0435 & 0.1260 & 0.996 \\
\hline
\end{tabular}

TABLE VIII

CALCULATED VALUES OF SIMILARITY PARAMETERS TWO MATERIALS

\begin{tabular}{cccc}
\hline Model No. & q* & $\begin{array}{c}\text { Method } \\
\theta *\end{array}$ & T* \\
\hline $2-1$ & 0.125 & 0.250 & 1.00 \\
$2-2$ & 0.0447 & 0.126 & 1.00 \\
\hline
\end{tabular}

Temperatures were measured following the test procedures described in Chapter IV. Tables IX through XII present the measured steady-state temperatures for the two prototypes, the measured model temperatures, and the prototype temperatures predicted from each model. These data 


\section{TABLE IX}

STEADY-STATE RESULTS

SINGLE MATERIAL,

LOW ENERGY INPUT

\begin{tabular}{|c|c|c|c|c|c|c|c|c|c|}
\hline \multirow[t]{2}{*}{$\begin{array}{l}\text { Model } \\
\text { No. }\end{array}$} & \multirow[t]{2}{*}{$\begin{array}{l}\text { Method of } \\
\text { Calculation }\end{array}$} & \multirow[t]{2}{*}{$\frac{q^{*}}{\text { Requined }}$} & \multirow[t]{2}{*}{$\begin{array}{c}q^{*} \\
\text { Actual }\end{array}$} & \multicolumn{3}{|c|}{$\begin{array}{l}\text { Measured } \\
\text { Temperatures }\left({ }^{\circ} \mathrm{F}\right)\end{array}$} & \multicolumn{3}{|c|}{$\begin{array}{l}\text { Predicted Prototype } \\
\text { Temperatures ( } \mathrm{F} \text { ) }\end{array}$} \\
\hline & & & & $T_{I}$ & $\mathrm{~T}_{2}$ & $\mathrm{~T}_{3}$ & $\mathrm{~T}_{1}$ & $\mathrm{~T}_{2}$ & $\mathrm{~T}_{3}$ \\
\hline Proto. I & - & - & $=$ & 61 & 51 & 43 & - & - & - \\
\hline $1-1$ & 2 & $0.664 ?$ & 0.6587 & 201 & 189 & 177 & 62 & 53 & 43 \\
\hline $1-1$ & 3 & 0.6288 & 0.6269 & 192 & 181 & 169 & 59 & 50 & 41 \\
\hline $1-2$ & 2 & 0.5200 & 0.5119 & 288 & 276 & 266 & 55 & 46 & 40 \\
\hline $1=3$ & 2 & 0.1231 & 0.1234 & 61 & $=$ & 45 & 62 & - & 46 \\
\hline $1-3$ & 3 & 0.1232 & 0.1234 & 61 & - & 45 & 62 & - & 46 \\
\hline $1-4$ & 2 & 0.0435 & 0.0436 & 49 & 40 & 33 & 51 & 42 & 35 \\
\hline $1-4$ & 3 & 0.0435 & 0.0436 & 49 & 40 & 33 & 50 & 42 & 35 \\
\hline
\end{tabular}




\section{TABLE X}

STEADY-STATE RESULTS,

SINGLE MATERIAL,

HIGH ENERGY INPUT

$q_{p}=44.00$ watts

\begin{tabular}{|c|c|c|c|c|c|c|c|c|c|}
\hline \multirow[t]{2}{*}{$\begin{array}{l}\text { Model } \\
\text { No. }\end{array}$} & \multirow[t]{2}{*}{$\begin{array}{l}\text { Method of } \\
\text { Calculation }\end{array}$} & \multirow[t]{2}{*}{$\frac{q^{*}}{\text { Required }}$} & \multirow[t]{2}{*}{$\begin{array}{c}q^{*} \\
\text { Actual }\end{array}$} & \multicolumn{3}{|c|}{$\begin{array}{l}\text { Measured } \\
\text { Temperatures }\left({ }^{\circ} \mathrm{F}\right)\end{array}$} & \multicolumn{3}{|c|}{$\begin{array}{l}\text { Predicted Prototype } \\
\left.\text { Temperatures ( }{ }^{\circ} \mathrm{F}\right)\end{array}$} \\
\hline & & & & $\mathrm{T}_{1}$ & $\mathrm{~T}_{2}$ & $T_{3}$ & $\mathrm{~T}_{1}$ & $\mathrm{~T}_{2}$ & $T_{3}$ \\
\hline Proto. 1 & - & - & - & 162 & 144 & 130 & - & - & - \\
\hline $1-1$ & 2 & 0.6647 & 0.6580 & 330 & 307 & 286 & 165 & 147 & 130 \\
\hline $1-1$ & 3 & 0.6288 & 0.6289 & 321 & 299 & 279 & 160 & 143 & 127 \\
\hline $1-3$ & 2 & 0.1231 & 0.1231 & 163 & - & 132 & 164 & - & 134 \\
\hline $1-3$ & 3 & 0.1232 & 0.1231 & 163 & $\infty$ & 132 & 164 & $\infty$ & 133 \\
\hline $1=4$ & 2 & 0.0435 & 0.0435 & 150 & 134 & 121 & 153 & 136 & 123 \\
\hline$I=4$ & 3 & 0.0435 & 0.0435 & 150 & 134 & .121 & 152 & 136 & 123 \\
\hline
\end{tabular}




\section{TABIE XI}

STEADY-STATE RESULTS

TWO MATERIAIS

IOW ENERGY INPUT

\begin{tabular}{|c|c|c|c|c|c|c|c|c|c|c|c|}
\hline \multirow[t]{2}{*}{$\begin{array}{l}\text { Model } \\
\text { No. }\end{array}$} & \multirow[t]{2}{*}{$\begin{array}{l}\text { Nethod of } \\
\text { Calculation }\end{array}$} & \multirow[t]{2}{*}{$q^{* *}$} & \multirow[t]{2}{*}{ Actual } & \multicolumn{4}{|c|}{$\begin{array}{l}\text { Measured } \\
\left.\text { Temperatures ( }{ }^{\circ} \mathrm{F}\right)\end{array}$} & \multicolumn{4}{|c|}{$\begin{array}{l}\text { Predicted Prototype } \\
\text { Temperatures ( } \mathrm{F} \text { ) }\end{array}$} \\
\hline & & & & $\mathrm{T}_{1}$ & $\mathrm{~T}_{2}$ & $\mathrm{~T}_{3}$ & $\mathrm{~T}_{4}$ & $\mathrm{~T}_{1}$ & $\mathrm{~T}_{2}$ & $\mathrm{~T}_{3}$ & $T_{4}$ \\
\hline Proto. 2 & - & - & - & 76 & 68 & 52 & 12 & - & - & $=$ & - \\
\hline $2-1$ & 1 & 0.125 & 0.125 & 75 & 66 & 49 & 10 & 75 & 66 & 49 & 10 \\
\hline $2-2$ & $I$ & 0.0447 & 0.0448 & 66 & 56 & 39 & 2 & 66 & 56 & 39 & 2 \\
\hline $2-2$ & 1 & 0.0447 & 0.0494 & 80 & 70 & 51 & 11 & 80 & 70 & 51 & 11 \\
\hline
\end{tabular}




\section{TABIE XII}

STEADY -STATE RESUITS

TWO MATERIAIS,

HIGH ENERGY INPUT

$q_{p}=43.95$ watts

\begin{tabular}{|c|c|c|c|c|c|c|c|c|c|c|c|}
\hline \multirow{2}{*}{$\begin{array}{c}\begin{array}{c}\text { Model } \\
\text { No. }\end{array} \\
\text { Proto. } 2\end{array}$} & \multirow{2}{*}{$\begin{array}{c}\text { Method of } \\
\text { Calculation } \\
-\end{array}$} & \multirow{2}{*}{$\frac{q^{*}}{\text { Required }}$} & \multirow{2}{*}{$\frac{\mathrm{q}^{*}}{\operatorname{ActuaI}}$} & \multicolumn{4}{|c|}{$\begin{array}{r}\text { Measured } \\
\text { Temperatures }\end{array}$} & \multicolumn{4}{|c|}{$\begin{array}{l}\text { Predicted Prototype } \\
\text { Temperatures }(\circ \mathrm{F})\end{array}$} \\
\hline & & & & 184 & 168 & 142 & 76 & - & - & - & - \\
\hline $2-1$ & $I$ & 0.125 & 0.125 & 186 & 168 & 141 & 76 & 186 & 168 & 141 & 76 \\
\hline $2-2$ & 1 & 0.0447 & 0.0446 & 178 & 160 & 131 & 69 & 178 & 160 & 131 & 69 \\
\hline $2-2$ & $I$ & 0.0447 & 0.0474 & 189 & 170 & 140 & 75 & 189 & 170 & 140 & 75 \\
\hline
\end{tabular}


were corrected for geometric scaling and property variaw tions with temperature (if applicable), according to the $T^{*}$ values in Tables VII and VIII. In addition to these corrections, another correction was required to compensate for an error which occurred during some tests in the energy input to the model. This input error occurred only during the tests of models $1-1$ and $1-2$. The method of making the correction is covered in detail in a later section.

Generally, there was excellent prediction of prototype temperatures from model data. The largest average absolute error for a particular model was 10 degrees and the smallest less than two degrees.

One of the objectives was to compare the results of Method 2 and Nethod 3 similarity parameters. Method 2 took into account the property variations with temperature while Method 3 did not. Both methods provided, excellent results. Using the tests on model l-1, scaled such that $R^{*}=I^{*}=0.50$ for the comparison, Nethod 2 had an average absolute error of 1.8 degrees (considering all six temperatures at two levels of energy input). Method 3 had the same average absolute error. On the basis of these results, both methods appear equally good. However", if a material with a greater temperature dependence of thermal conductivity had been used, perhaps a more definitive comparison could have been made. 
The results for model $1-2$, having $R^{*}=I^{*}=0.331$, using the Method 2 parameters, were not quite as good as those for model 1-1, having an average absolute error of 4.7 degrees. This was, however, still better than any previous experimental work in the field. No high level input data were obtained because of the excessively high temperatures which would have resulted in the model.

The results provided by model $1-3$, scaled such that $\mathrm{R}^{*} \approx \mathrm{I}^{* 2}$, were excelient. The predicted prototype temperatures had an average absolute error of 2.8 degrees. The Method 2 parameters were used since the Method 1 requirement of $R^{*}=I^{* 2}$ was not exactly fulfilled. This test was repeated as a check on reproducibility. The measured temperatures were repeated to within 0.5 degrees for both static and dynamic portions of the test. The center thermocouple on the model was located incorrectly, consequently only two locations were comparable.

Using the Method 3 parameters for a third comparison from same model, the average abolute error was 2.5 degrees. There was essentially no difference in the predicted prow totype temperature using this method, as compared to Method 2。

Mode1 1-4, also described by the Method 2 parameters, had an average absolute error of 8.5 degrees. The most probable cause of this error, as discussed later in con nection with the results of model 2-2, was the loss 
through the heater lead wires. Because of the extremely low power input to this model ( 0.961 and 1.912 watts) the lead loss was appreciable. The Method 3 parameters gave almost identical results。

The two material model 2-1, described by the parameters of Method 1, provided excellent results, having an average absolute error of 1.3 degrees for the four temperatures at each of two energy levels.

Model 2-2 did not provide results as close as model 2-1, but the predicted temperatures were still very good. The average absolute error was 9.6 degrees. As with model 1-4, the loss through the heater leads was suspected as causing the error. Consequently, the heater lead loss was calculated to be 10.2 per cent and 8.2 per cent of the energy input for the low and high levels, respectively, and a second test was performed, increasing the heater input by 10.3 per cent and 6.2 per cent. The results were much improved, having an average absolute error of 2.3 degrees. The first steady-state condition imposed on the model indicated that the heater lead loss had been over estimated, so the input change for the second steadyostate condition was reduced to a 6.2 per cent increase rather than the calculated 8.2 per cent.

\section{Transient Results}

Time-variable temperatures were obtained by making a 
step increase of heater input power. The change was made after establishing thermal equilibrium at the lower energy input. The time that the power change was made was recorded as zero time. Temperatures and elapsed times were subsequently recorded until a new thermal equilibrium was established. Transient data were recorded for all models except Model 2-1, where the high level input temperatures would have been excesaive.

Figures 1 through 9 present the measured temperaturetime data for the two prototypes, and the prototype tem peratures and times predicted from each model. These data were corrected for geometric scaling and property variations with temperature, if applicable, according to the calculated similarity parameters of Tables VII and VIII. Transient corrections for error in heater power input were made only on the test for Model 1-1, Method 2, where the average steady-state correction was +5.3 degrees. Since the percentage correction was essentially the same for both levels of energy input, the correction was considered valid. The only other test which had a significant power input error was the low input part of the test on Model 1-1, wh the Method 3 parameters. The static correction averaged only + 1 degree. No correction was necessary on the high input part of the test, consequently no energy input corrections were made on these transient data. 
Figures 1 and 6 present the data for the single material and two material prototypes, respectively。 Figures 2 through 5 and $?$ through 9 reproduce the data for the prototypes as a solid curve and the data points are those calculated for the prototype from the particular model.

For model 1-1, using the Method 2 parameters, Figure 2 shows that the transient errors were at no time larger than the steady-state errors: all temperatures were within three degrees of the measured prototype temperatures. The Method 3 parameters predicted temperatures consistently on the low side, but with a maximum deviation of only six degrees during the transient period (Figure 3)。

Figure 4 presents the results of the tests for model 1-3, using the Method 2 parameters. The transient results averaged no more than two degrees different than the measurea prototype temperatures.

The data for model 1-4, Figure 5, with the Method 2 parameters, were plotted in a rather peculiar manner to emphasize a point. The model temperature data have had a constant 10 degrees added to them to demonstrate that the time variation of temperature predicted by the model was correct, even though there was a steady-state error of 7 to 10 degrees. This steady-state error was briefly discussed earlier and will be covered in detail in a later section。

The results from model 2-1, Figure 7 , which predicted 
the temperatures of the two material prototype, were excellent. The transient errors were no larger than the steady-state errors, which averaged -1.3 degrees, with a maximum deviation of -3 degrees.

The data for model 2-2 test 1 , as with mode1 1-4 data, have had a constant added before plotting to show more clearly that the error was principally a static one and not dynamic. The constant factor in this case was also 10 degrees.

The results of the second test of model 2-2, with inm creased input to account for heater lead losses, are given in Figure 9. As with previous results, the transient errors were no greater than the static errors, which had an average absolute value of 2.3 degrees, and a maximum deviation of 5 degrees.

\section{Error Analysis}

Instrumentation and measurement errors were discussea in Chapter IV. The purpose of this section is to discuss the possible effects caused by such factors as incorrect energy input to the model, energy losses through thermocouple leads and support wires, heater insulation and heater leads, and the possible effects caused by the thero mal conductivity and specific heat not being the same for both model and prototype. 


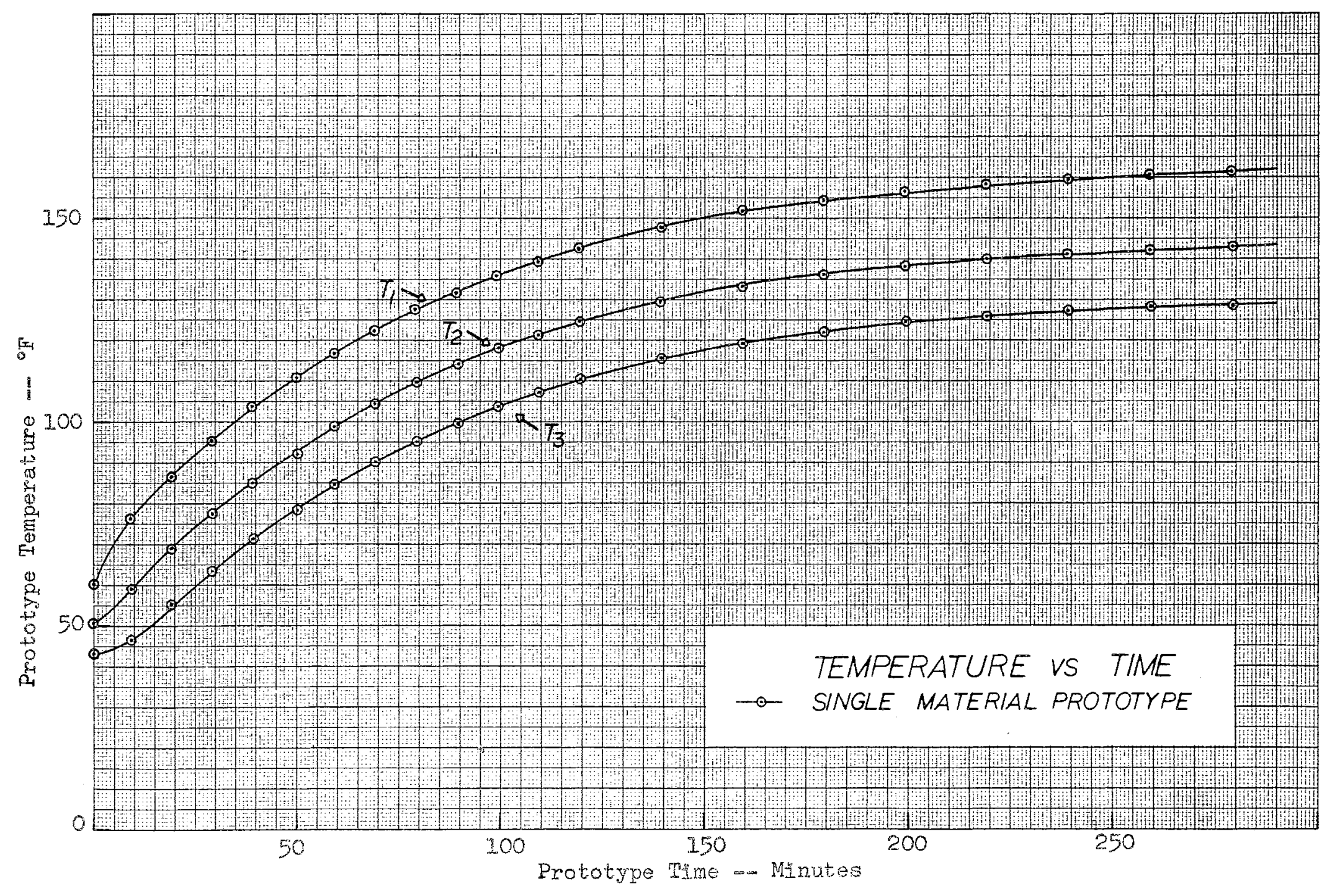

Figure 1. Temperature Versus Time, Single Material Frototype 


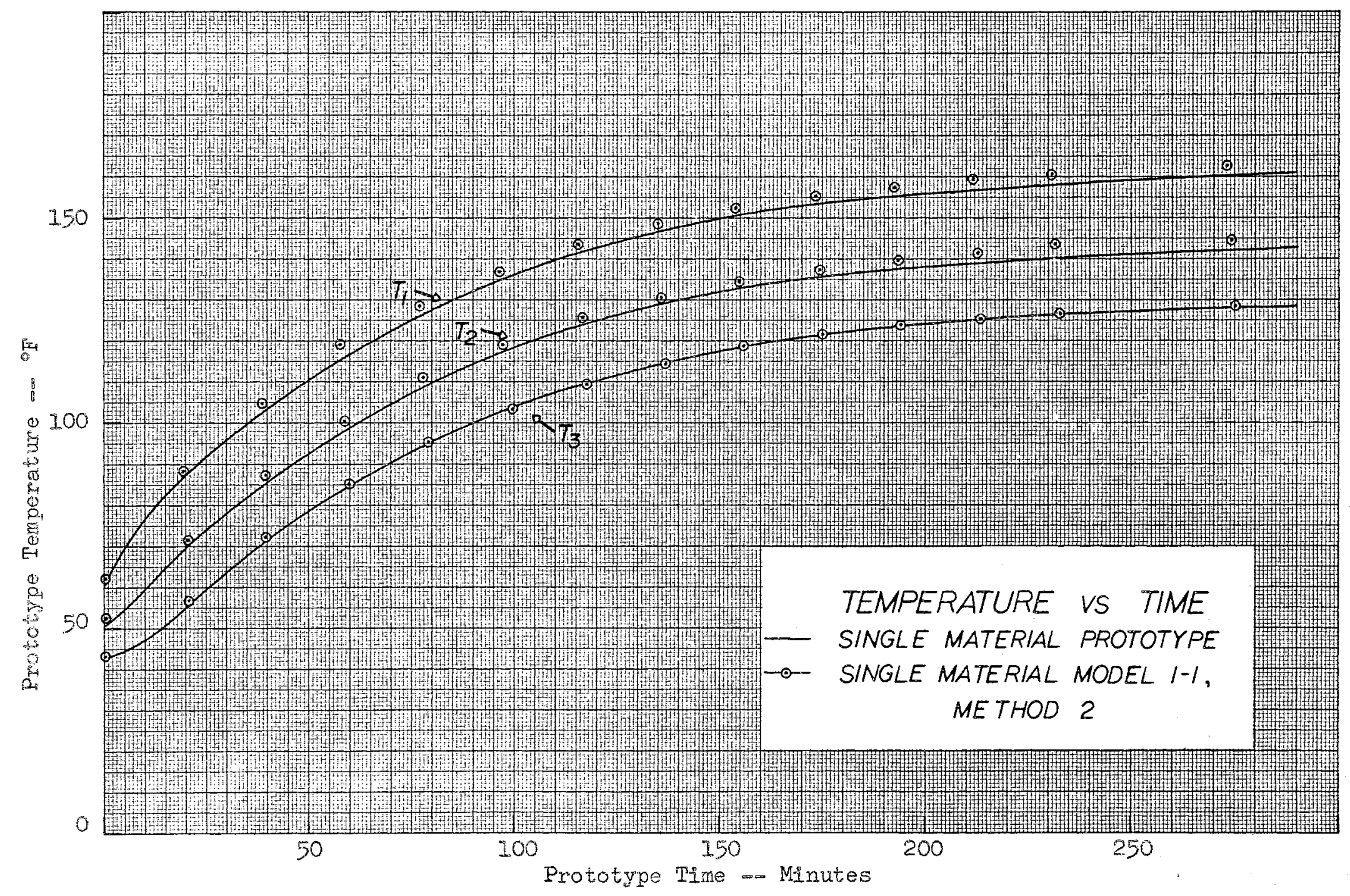

Figure 2. Single Material Prototype Temperatures Predicted From Model l-I, Method 2 


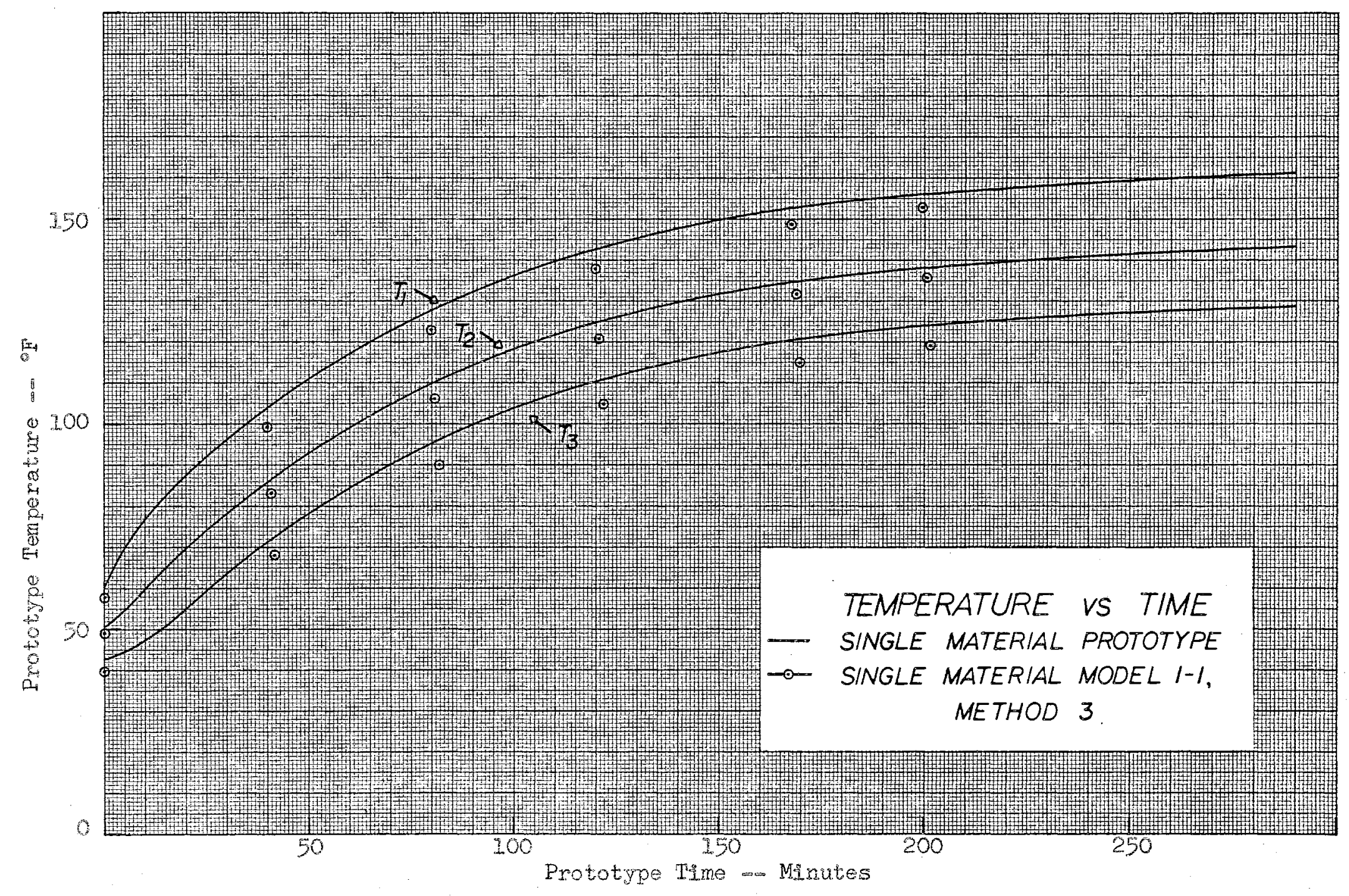

Figure 3. Single Material Prototype Temperatures Predicted From Model 1-I. Method 3 G 


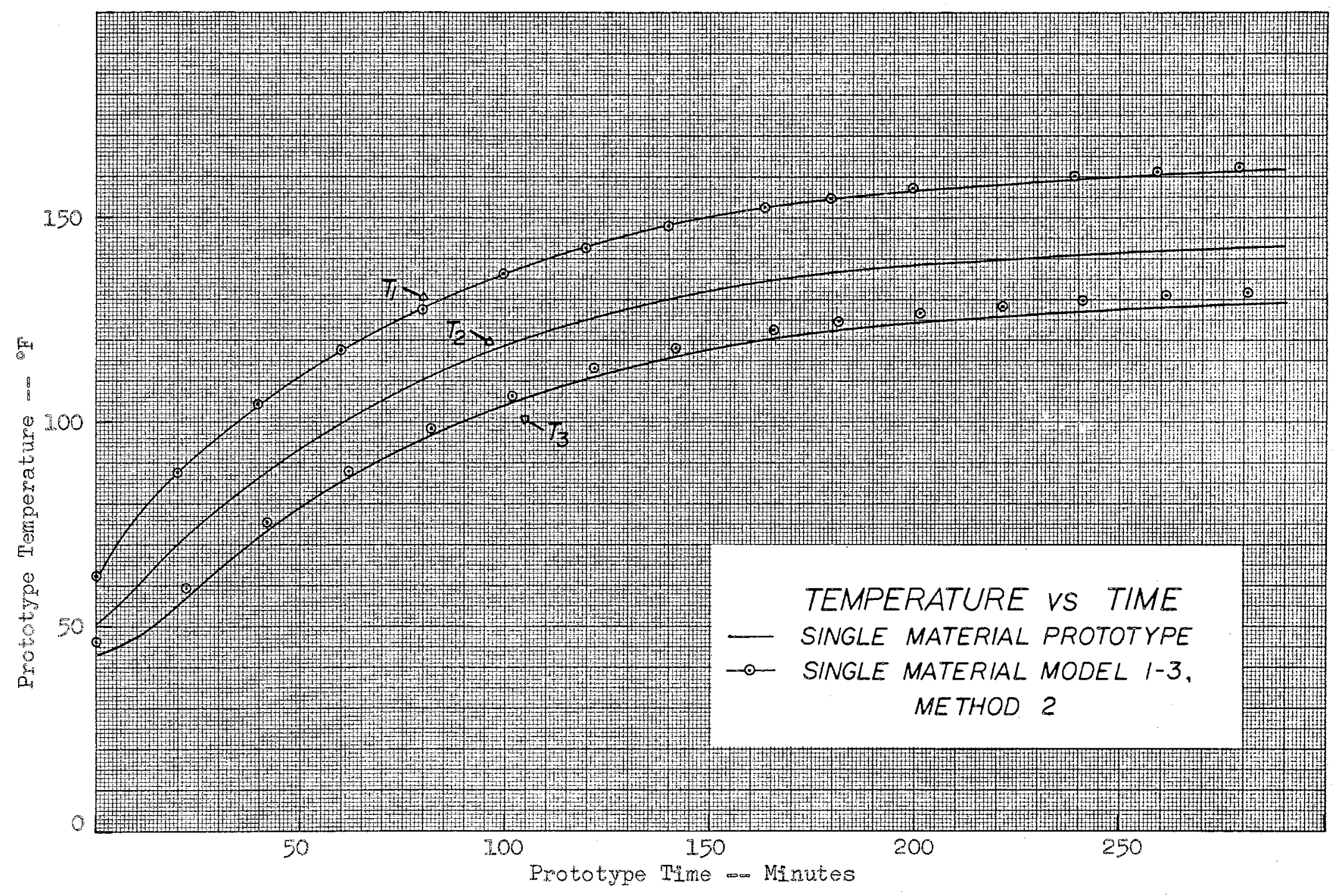

Tigure 4. Single Material Prototype Temperatures Predicted From Model 1-3, Method 2 


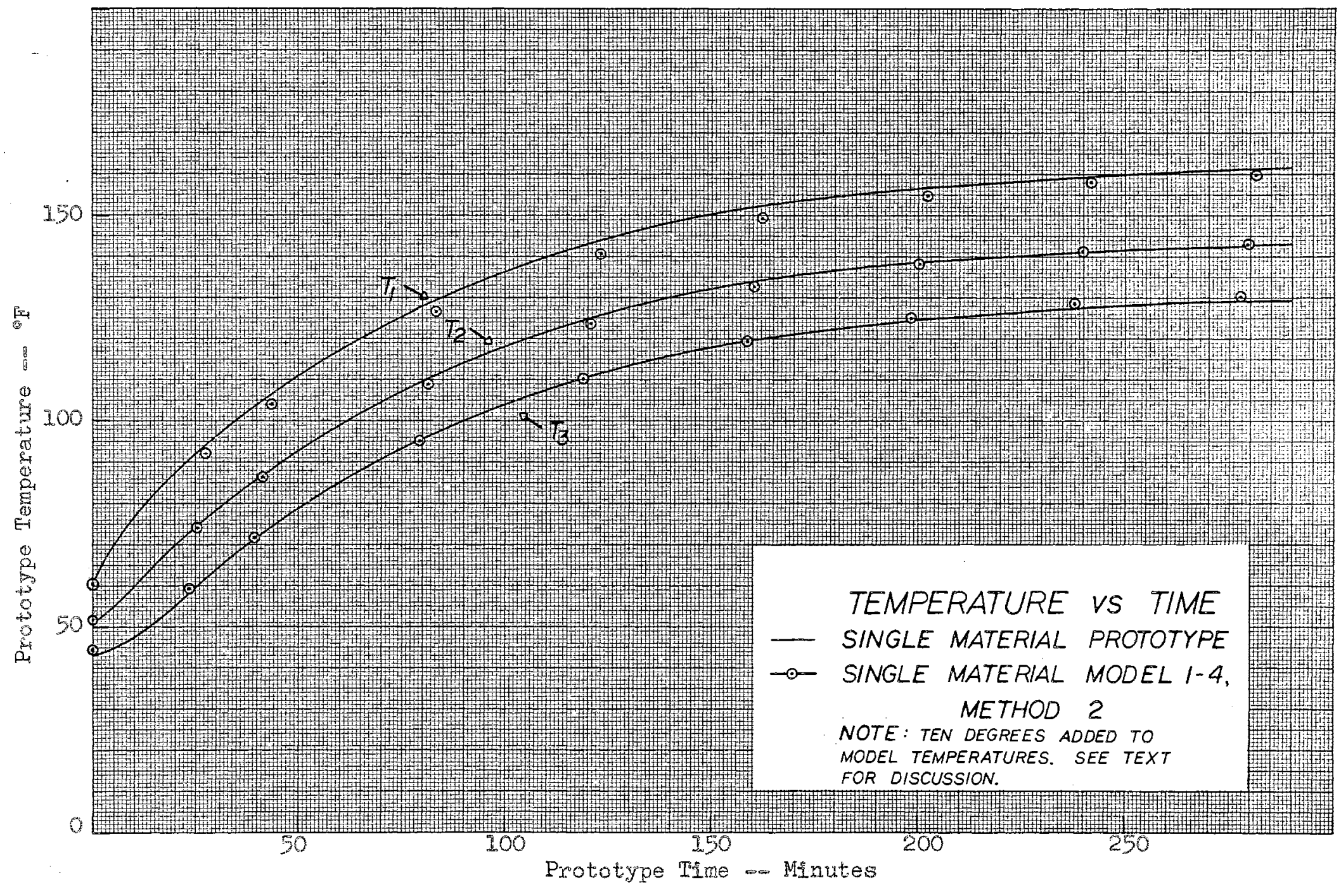

Figure 5. Single Material Prototype Temperatures Predicted From Model 1-4, Method 2 


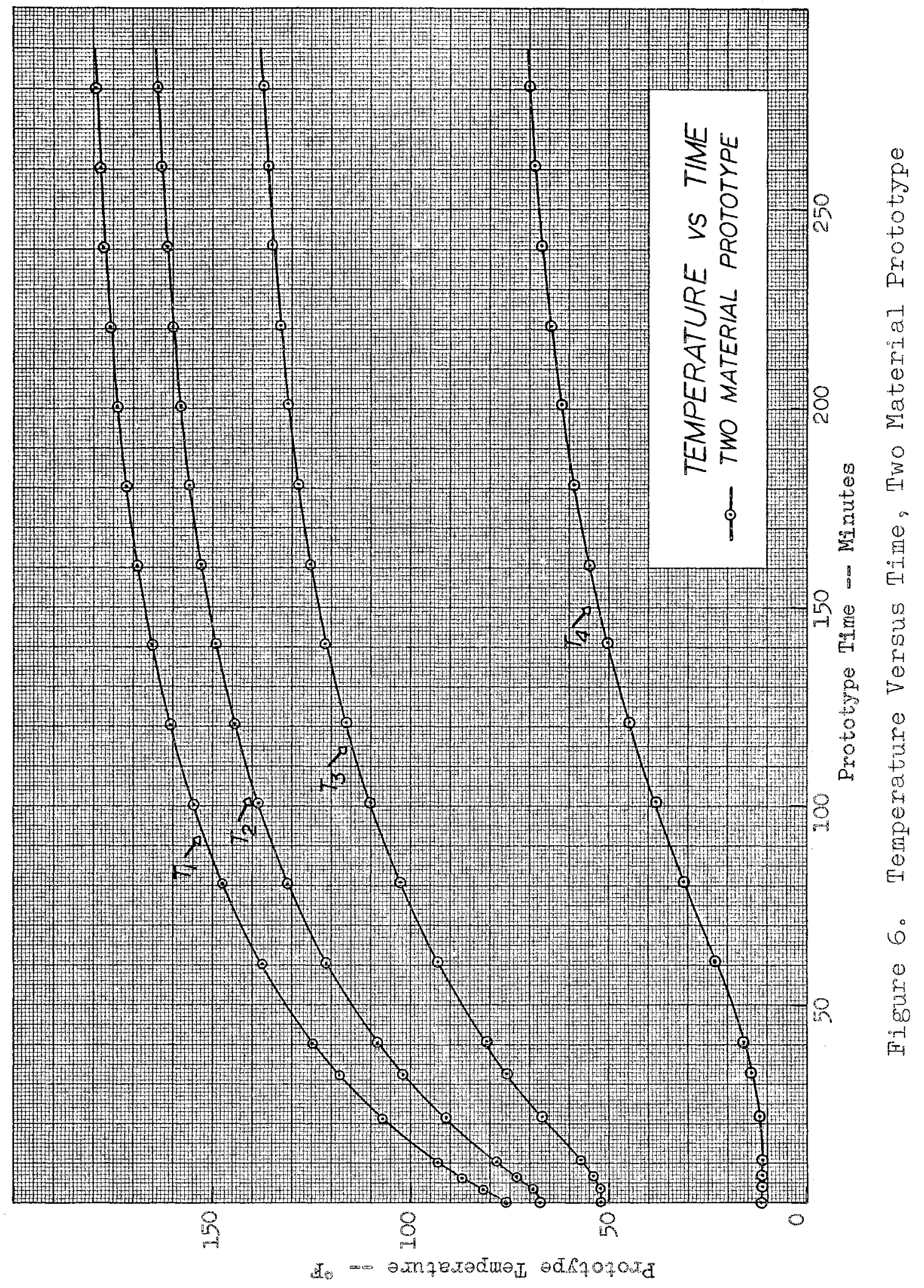




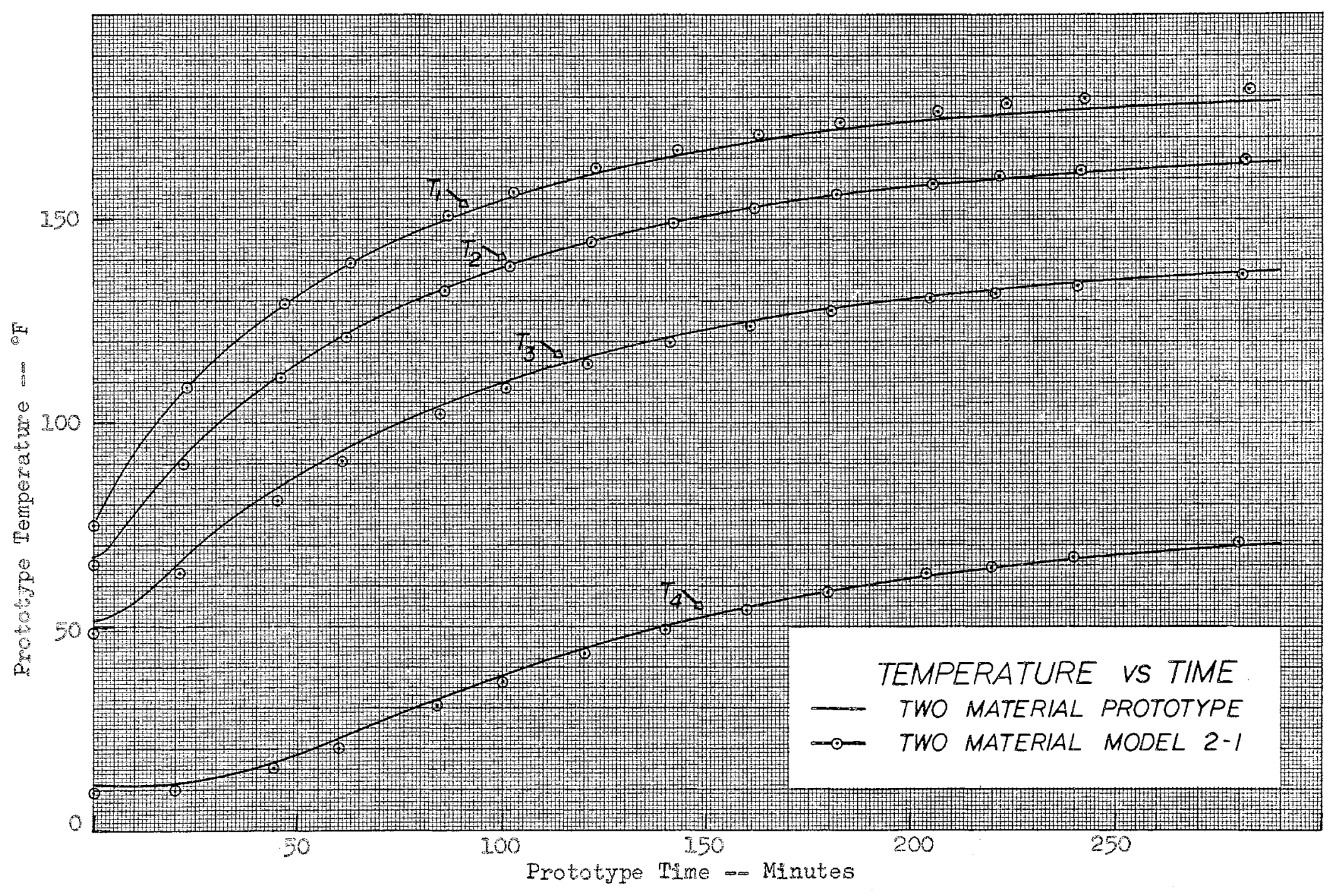

Figure 7. Two Material Frototype Temperatures Predicted From Model 2-1 


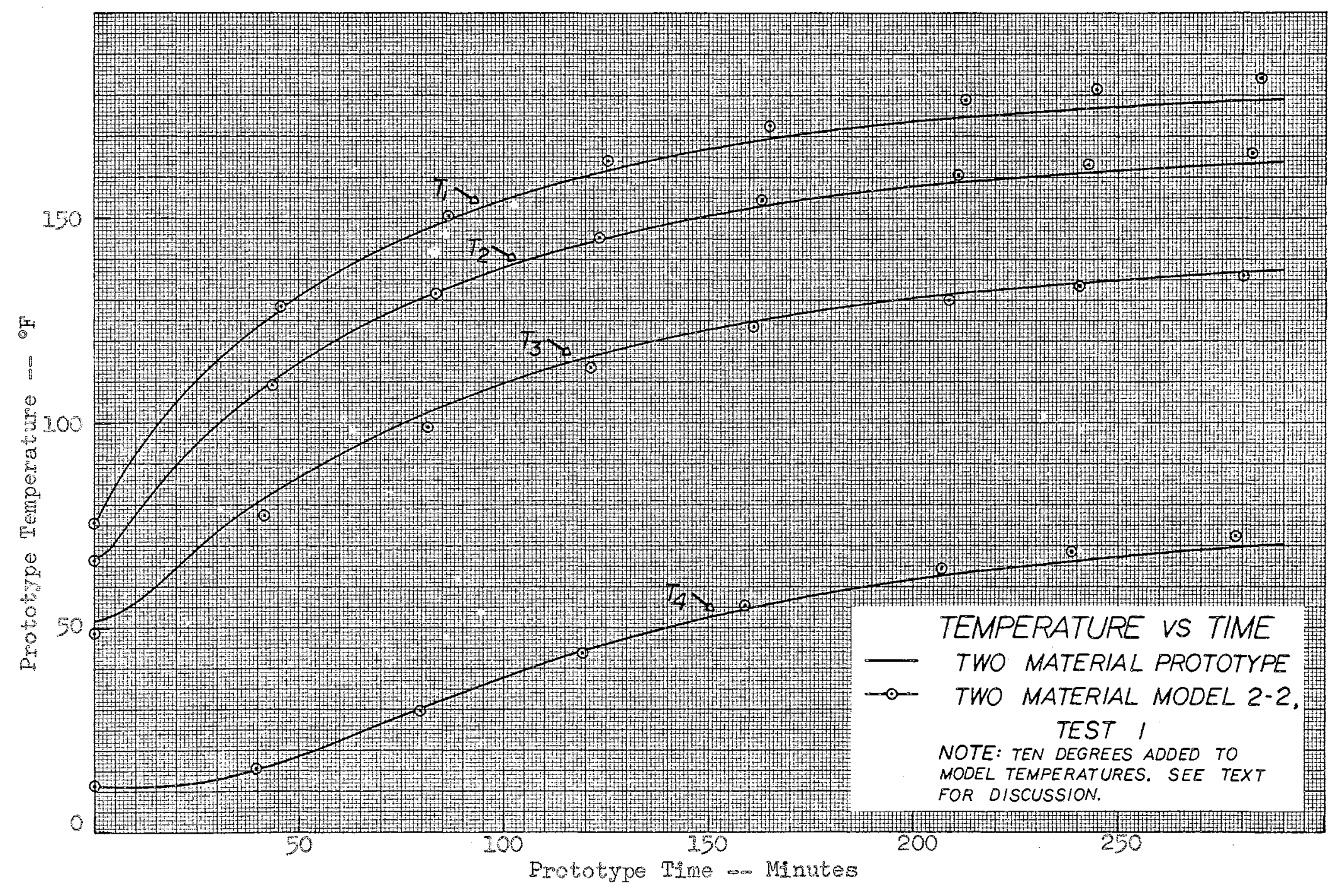

Figure 8. Two Material Prototype Temperatures Predicted From Model 2-2; Test I 


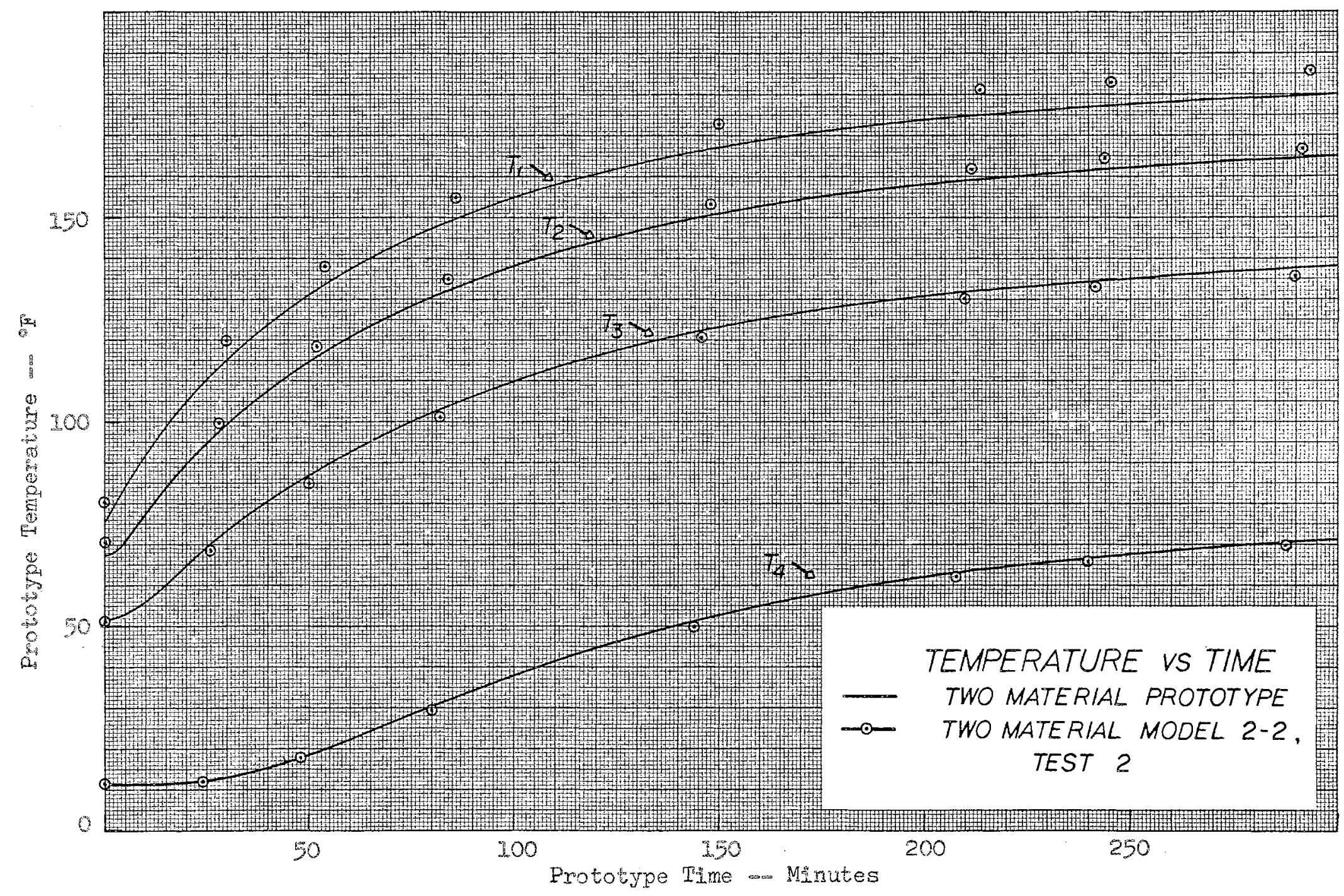

Figure 9. Two Material Prototype Temperatures Predicted From Model 2-2, Test 2 


\section{Incorrect Energy Input}

If the heater input to the model is different than required by the similarity parameters, a first approxim mation to the effect of this error may be made by combining the Method 2 similarity parameters for heat transfer ( $\left.q^{*}\right)$ and temperature (T*); Parameters (2-6I) and (2-62) of Table I. If this is done, the following equation is obtained.

$$
T^{*}=q^{*}\left[\frac{L^{*}(3+a)}{R^{*}(6-a)}\right]^{\frac{2}{3-a}}
$$

This equation indicates that a given percentage error in $q^{*}$ will cause an equal percentage error in $T^{*}$. As an example, the low input test for model $1-2$ had a $q^{*}$ value 1.58 per cent lower than it should have been. This results in a $T^{*}$ value 1.58 per cent smaller than the $T^{*}$ value calculated from purely geometric considerations. The temperature correction for model $1-2$, due to the low value of $q^{*}$, was +8 degrees.

This same procedure was used on the model I-l tests. The high and low input energies, using the Method 2 parameters, were both one per cent low resulting in an average +5.3 degree correction. Only the low input was incorrect for the test using the Method 3 parameters, a $\infty .3$ per cent error resulting in $a+l$ degree correction. All other 
tests had actual $q$ * values within 0.2 per cent of their required value.

Thermocouple and Support Wire Losses

Thermocouple and support wire losses may be estimated by considering the thermocouple leads as infinitely long pin fins with a known root temperature, and with radiation heat transfer from the fin surface. The differential equation describing this situation is:

$$
k R \frac{d^{2} T}{d x^{2}}=2 \varepsilon \sigma T^{4}
$$

This equation may be integrated once with respect to $x$ to yield the heat transfer rate at the root of the fin, the desired quantity。

$$
\left.q_{0}=-k A_{n} \frac{d T}{d x}\right]_{X=0}=\left[\frac{4}{5} \pi^{2} R^{3} k \varepsilon \sigma\left(T_{0}^{5}-T_{\infty}^{5}\right)\right]^{\frac{1}{2}}
$$

The wire radii were known from tabulated values for wire gages. Thermal conductivities of $220 \mathrm{~B} / \mathrm{hr}-\mathrm{ft}-\mathrm{F}$ and $14 \mathrm{~B} / \mathrm{hr}-\mathrm{ft}-\mathrm{F}$ for copper and constantan, respectively, were used in calculations. The surface emittance values were estimated for the polished wires as 0.05 for copper and 0.10 for constantan. Measured values were used for $T_{0}$ and $\mathrm{T}_{\infty}$ was assumed to be $150^{\circ} \mathrm{R}$, the boiling temperature of liquid nitrogen。

Tables XIII and XIV include values for the total 
thermocouple and support wire losses for each model. All are less than 0.5 per cent except for the smallest models, 1-4 and 2-2, where they were still less than one per cent.

Heater Insulation Iosses

Losses through the heater insulation were estimated from charts predicting the insulation value of "NRC-2," published by National Research Corporation (11)。All models had 10 wraps of insulation, applied at an estimated density of 60 to 80 layers per inch of thickness. Tables XIII and XIV include these losses, calculated for each model and level of energy input. All were 0.2 per cent on less.

\section{Heater Lead Iosses}

The copper heater leads were brought out from the heater through the fifth and sixth layers of "NRC-2" insulation. Thus, the first portion of the leads was insulated against radiation losses. The lead losses were estimated by assuming the heat conducted from the point of attachment to the heater, along the insulated portion of the lead wires, was then radiated away by an infinitely long pinfin, the second part of the lead wires. The length of lead wire inside the insulation was the same length as the insulated heater section. The beginning of the heater lead wire was assumed to be at the same temperature as the thermocouple closest to the heater. 
The heat transfer along the heater lead may be writum ten as

$$
q_{0}=\frac{k \pi R^{2}\left(T_{0}-T_{1}\right)}{L} .
$$

This same amount of heat transfer must be radiated away from the second part of the heater wire, acting as an infinite pin fin。

$$
q_{0}=\left[\frac{4}{5} \pi^{2} R^{3} k \varepsilon \sigma\left(T_{1}^{5}-T_{\infty}^{5}\right)\right]^{\frac{1}{2}}
$$

In these equations, $R$ is the lead wire metal radius, $k$ is the thermal conductivity of the lead wire, $I$ is the length of wire inside the "NRC-2" insulation, and $T_{I}$ is the wire temperature at the exit from the insulation.

The cotton insulation was measured as 0.005 inches thick, and was assumed to have an enittance of 0.95 . The cotton was also assumed to be at the same temperature as the interior copper wire.

Equations $(5-4)$ and $(5-5)$ were equated so the only unknown was $T_{1}$, which was determined by trial and error. The heat loss through the heater leads was then calculated from Equation (5-4). The calculated values are presented in Tables XIII and XIV。

The heater lead losses were appreciable, ranging from a low of less than one per cent for the prototypes to over 10 per cent for the smaller models. It was originally believed that the heater losses could be treated simply as 
a decreased energy input and a corrected temperature calculated from Equation (5-1). As an example, this assump tion would have increased the prototype temperatures predicted by model 2-2 test 1 , low input, by approximately $50^{\circ} \mathrm{F}$. To check this further, a second test was performed on model 2-2, increasing the input by the amount of the calculated heater losses. The results indicated an average temperature increase of only 12.6 degrees and provided very good agreement between predicted and actual prototype temperatures. These results indicate that the use of Equaw tion (5-1) is not valid if losses are this large.

\section{Variation of Thermal Properties}

In the derivation of the similarity parameters of Table I, it was assumed that model and prototype were constructed of the same material, which implies that thermal conductivity and specific heat were equal in model and prototype. Since the percentage of alloying elements for a particular material is not the same for each batch from a particular manufacturer or for materials with the same alloy specifications from different manufacturers, there was a possibility that model and prototype had slightly different thermal properties.

The material properties were assumed to vary with temperature according to the relationships:

$$
k=k_{0} T^{a}
$$




\section{TABIE XIII}

\section{CAICUIATED ENERGY LOSSES \\ SINGLE MATERIAL, STEADY-STATE}

Low Energy Input

\begin{tabular}{cccc}
\hline Model No. & \multicolumn{2}{c}{ Toss in Per Cent of Energy $\begin{array}{c}\text { Input } \\
\text { Heater Wire }\end{array}$} \\
\hline Proto 1 & 0.35 & 0.16 & 0.69 \\
$1-1$ & 0.31 & 0.17 & 2.11 \\
$1-2$ & 0.17 & 0.15 & 3.91 \\
$1-3$ & 0.30 & 0.15 & 3.49 \\
$1-4$ & 0.73 & 0.16 & 10.20 \\
\hline
\end{tabular}

High Energy Input

\begin{tabular}{cccc}
\hline Model No. & \multicolumn{2}{c}{ Toss in Per Cent of Energy Input } \\
Insulation & Heater Wire \\
\hline Proto 1 & 0.27 & 0.18 & 0.49 \\
$1-1$ & 0.24 & 0.15 & 1.52 \\
$1-3$ & 0.22 & 0.18 & 2.55 \\
$1-4$ & 0.63 & 0.18 & 7.74 \\
\hline
\end{tabular}




\section{TABLE XIV \\ CALCULATED ENERGY IOSSES \\ TWO MATERIAL, \\ STEADY-STATE}

Low Energy Input

\begin{tabular}{cccc}
\hline Model No. & Thermocouples & $\begin{array}{c}\text { Loss in Per Cent of Energy Input } \\
\text { Insulation }\end{array}$ & Heater Wire \\
\hline Proto 2 & 0.49 & 0.20 & 0.73 \\
$2-1$ & 0.33 & 0.20 & 3.96 \\
$2-2$ & 0.91 & 0.20 & 10.6 \\
\hline
\end{tabular}

High Energy Input

Loss in Per Cent of Energy Input

\begin{tabular}{cccc} 
Model No. & Thermocouples & Insulation & Heater Wire \\
\hline Proto 2 & 0.34 & 0.20 & 0.53 \\
$2-1$ & 0.25 & 0.20 & 2.69 \\
$2-2$ & 0.71 & 0.20 & 8.18 \\
\hline
\end{tabular}




$$
c_{p}=c_{p o} T^{b}
$$

The effects of the variation, from lot-to-lot, of the conductivity and specific heat on the value of the modeling parameters may be illustrated by assuming that the exponents in the power law equations are the same for both model and prototype and determining the effect of the variations of $k_{0}$ and $c_{\text {po }}$ of course, the exponents may also vary for a given material, from lot-towlot, but the illustration is adequate by observing the effects of variations of $\mathrm{k}_{\mathrm{o}}$ and $\mathrm{c}_{\mathrm{po}}{ }^{\circ}$

With these assumptions, the Method 2 similarity parameters, Equations (2-45) through (2-47), may be rewritw ten to include $k_{0}^{*}=\frac{k_{o m}}{k_{o p}}$, which was previously assumed to have a value of unity.

$$
\begin{aligned}
& q^{*}=\left(k_{0}^{*}\right)^{\frac{4}{3-a}}\left(\frac{R^{*}(7-a)}{L^{*}(5+a)}\right)^{\frac{1}{3-a}} \\
& \theta^{*}=c_{0}^{*}\left(\frac{1}{k_{0}^{*}}\right)^{\frac{3-b}{3-a}}\left(\frac{R^{*}(b-a)}{L^{*}(2 b-b)}\right)^{\frac{1}{3-a}} \\
& T^{*}=\left(k_{0}^{*}\right)^{\frac{1}{3-a}\left(\frac{R^{*}}{L^{*}}\right)^{\frac{1}{3-a}}}
\end{aligned}
$$

Using the property constants for 2024 aluminum as given in Table III, variations in the similarity parameters with a specified variation in $k_{0}^{*}$ may be calculated. as presented in Table XV. 
TABLE XV

SIMILARITY PARAMETER VARIATIONS WITH VARIATIONS OF $\mathrm{K}_{0}^{*}$

\begin{tabular}{|c|c|c|}
\hline Parameter & $\pm 1 \%$ & $\pm 3 \%$ \\
\hline$q^{*}$ & $\pm 1.4 \%$ & $\pm 4.3 \%$ \\
\hline$\theta *$ & $\mp 0.5 \%$ & $\mp 2.8 \%$ \\
\hline $\mathrm{T}^{*}$ & $\pm 0.3 \%$ & $\pm 1.0 \%$ \\
\hline
\end{tabular}

The principal error would be caused by an incorrect value being used for $q^{*}$. According to Equation (5-1), this would cause an equal percentage error in the value of T*, as compared to the value calculated from strictly geometric considerations.

Equation (5-7) indicates that $\theta *$ would be the only parameter affected by variations of c po: a given percentage error in $c_{p o}^{*}$ causing an equal percentage error in $\theta^{*}$ 。 In view of the magnitude of errors caused by variations of $k_{0}^{*}$ and $c_{p o}^{*}$, caution must be exercised that model and prototype are constructed of material with identical properties. The material used in this research was purchased from the same manufacturer, at the same time, with one exception. The material for model l-2 was of unknown origin. 
CHAPTER VI

CONCLUSIONS AND RECOMMENDATIONS

The objective of this dissertation was to investigate the applicability of thermal modeling to steady-state and transient thermal conditions, for both single and multiple material systems, taking into account changes of material properties with temperature.

The objective was satisfied with an analytical derivation of similarity parameters for thermal modeling which were experimentally verified. The results were subjected to an exhaustive analysis of possible errors, one of which was, to a first approximation, compensated by analytical techniques, and one of which was predicted prior to testing and eliminated with experimental techniques. These methods of analysis should be usefui for fuw sume work in thernel modeling.

The procedure which allowed thermal modeling to be accomplished while meeting all objectives was a choice of geometric scaling factors. Although the experimental work was accomplished using solid cylindrical systems, the re-w sults may be extended to include flat plates and hollow cylinders which have the thickness dimension scaled as the 
square of the length dimensions. The derivation of these parameters is included as an appendix. These are all essentially two dimensional shapes with predominately one dimensional conduction heat transfer. However, their combination in various ways could be used to approximate quite well a more complicated configuration.

No previous method had been proposed for the transient modeling of joined materials, although Chao and Wedekind (3) discussed the problem in the literature. An additional benefit of this scaling procedure is that model and prototype temperatures are equal. Previous material preservation methods required model temperatures higher than prototype temperatures by an amount related to the reduction in model size. For small scale models, temperatures rapidly became excessive. Previous authors have made the assumption that the ratios $T / L$ and $T / \theta$ could be substituted for the derivatives dT/dL and dT/de. These substitutions were made with reservation by this writer in the derivation of the Methods 2 and 3 parameters. The substitution is not logically correct. The derivation of the Method I parameters does not make these substitutions and the consequence is that there is temperature preservation between model and prototype, an apparent necessity for proper thermal modeling。

Previous experimental work had been done in transient and steadyowtate modeling of single material systems using either "temperature preservation" or "material preservation" 
techniques. However, the experimental inaccuracies incurred for various reasons precluded the prediction of prototype temperatures closer than 15 to 25 degrees. This dissertation presents results for which no predicted prow totype temperature was more than 13 degrees in error and the great majority of temperatures were consistently less than 5 degrees in error. Experimental results with this degree of accuracy permits the conclusion that the similarity parameters derived are valid for use in the design of spacecraft and other related applications.

The error analysis provided a method for correcting errors in model energy input which are incorrect by a constant percentage. The method is not exact but allows small corrections to be made. The error analysis and experimental results also prove that it is possible to predict in advance and experimentally compensate for lead losses at electrical heaters. These losses are very difficult to eliminate or design so that the model losses are in the correct proportion to the prototype Iosses.

The next logical step for future work in thermal modeling is the determination of the effect of not having perfect geometric similarity when a modeled system can "see" other portions of itself. The inclusion of simulated solar radiation also needs recognition in future investigations。 
(1) Vickers, J. M. F. "Thermal Scale Modeling," Astronautics and Aeronautics, May, 1965, 34-39.

(2) Jones, B.P. "Thermal Similitude Studies," J. $\frac{\text { Spacecraft, }}{364-69}$. 1 . No. 4, July-Aug., 1964,

(3) Chao, B. To, and G. I. Wedekind. "Similarity Criteria for Thermal Modeling of Spacecraft," J Spacecraft, Vol. 2, No. 2, March-April, 19̄65, $146-52$.

(4) Fowle, A. A., and F. Gabron, "Thermal Scale Modeling of Spacecraft: An Experimental Investigation." Reports on contract research by A.D. Little, Inc. for Jet Propulsion Laboratory, Pasadena, California. Phase I, Sept.s 1962; Phase II, June, 1963: Phase III, March, 1964.

(5) Vickers, J.M.F. "A Study of Thermal Scale Modeling Techniques," Technical Memorandum No. 33153, Jet Propulsion Laboratory, Pasadena, California, September," 1963

(6) Gabron, F, and R.W. Johnson. "Thermal Scale Modeling of the Temperature Control Model of Mariner Mars 64." Reports on contract research by A. D. Little, Inc for Jet Propulsion Laboratory, Pasadena, California. Phase IA, May, 1964: Phase IB, July, 1964: Phase II, January, 1965.

(7) Rolling, R. E. "Results of Transient Thermal Modeling in a Simulated Space Environment." Presented at the AIAA Thermophysics Specialists Conference, Monterey, California, Sept., 1965.

(8) Gabron, $F_{0}$, and $R$. Wo Johnson: "Thermal Scale Modeling of the Mariner IV Spacecraft." Presented at the AIAA Aerospace Science Meeting? New York, N. Y., January, 1966. 
(9) Adkins, D. I. "Scaling of Transient Temperature Distributions of Simple Bodies in a Space Chamber." Presented at the AIAA Thermophysics Specialists Conference, Monterey, California, September, 1965.

(10) Lucks, G.F., and H.W. Deem. "Thermal Properties of Thirteen Metals." American Society for Testing Materials Special Tech。Pub.227, 1958.

(11) "NRC-2 Insulation." National Research Corporation, Cambriage, Mass., 1962.

(12) Jones, B. P., and J. K. Harrison. "A Set of Experiments in Thermal Similitude." Marshall Space Flight Center, Huntsville, Alabama, NASA TM X53346, October, 1965.

(13) Shih, C. "Thermal Similitude of Manned Spacecraft。" Presented at the AIAA Aerospace Sciences Meeting, New York, N. Y., January, 1966. 


\section{APPENDIX I}

\section{SIMILARITY PARAMETERS FOR A FLAT PLATE \\ AND HOLLOW CYLINDER}

The similarity parameters for the thermal modeling of a flat plate may be derived using the same procedure as used in Chapter II for solid cylindrical shapes. In fact, the procedure is exactly the same, with the same assumptions, up to the point of inserting dimensional relations which describe the shape of the system to be modeled.

A flat plate may be described by a thickness, a length and a width dimension. It is assumed that the plate is large enough that edge effects are negligible, and that the length and width dimensions are scaled by the same factor (i.e., $L_{x}^{*}=I_{y}^{*}=L^{*}$ ). The principal conduction heat transfer direction is along the length of the plate, not through the thickness. This shape could be called a radiating fin. The ratio of areas normal to conduction heat transfer is expressed by the equation

$$
A_{n}^{*}=t^{*} L^{*}
$$

and the ratio of surface areas for radiation may be written as 


$$
A_{S}^{*}=I^{* 2}
$$

Substituting these relationships into Equations (2-14) through (2-19), there is obtained

$$
\begin{aligned}
q^{\prime \prime \prime} & =\frac{1}{t^{*}} \\
q^{\prime \prime} & =\frac{L^{*}}{t^{*}} \\
q^{*} & =L^{* 2} \\
T^{*} & =1 \\
\theta * & =\left(\rho c_{p}\right)^{*} t^{*} \\
k^{*} & =\frac{L^{* 2}}{t^{*}} .
\end{aligned}
$$

If the same material is to be used for model and prototype, it follows that $\left(\rho c_{p}\right)^{*}=k^{*}=1$, and the equations may be rewritten as:

$$
\begin{aligned}
& q^{\prime \prime *}=L^{*-2} \\
& q^{\prime *}=L^{*-1} \\
& q^{*}=L^{* 2} \\
& T^{*}=I \\
& \theta *=L^{* 2} \\
& t^{*}=L^{* 2}
\end{aligned}
$$

It is noted that these equations correspond exactly 
to the Method I paramaters of Table I, with the exception of the $q^{*}$ parameter, which was a length ratio to the third power for the solid cylindrical shape.

The Methods 2 and 3 parameters may be derived in a similar manner, beginning with Equations (2-26) through (2-31), written in a form which includes the area relationships.

$$
\begin{aligned}
& q^{\prime \prime \prime *}=\frac{K^{*} T^{*}}{L^{* 2}} \\
& q^{\prime \prime} *=\frac{k^{*} T^{*}}{I^{*}} \\
& \mathrm{q}^{*}=\frac{\mathrm{k}^{*} \mathrm{~A}_{\mathrm{n}} \mathrm{T}^{*}}{\mathrm{I}^{*}} \\
& \theta *=\left(\rho c_{p}\right) * \frac{L^{* 2}}{k^{*}} \\
& T^{*}=\left(\frac{A_{n}^{*} K^{*}}{A_{S}^{*} L^{*}}\right)^{I / 3} \\
& T^{*}=\frac{A_{S}{ }^{*} L^{*}}{k^{*} A_{n}{ }^{*}} \text {. }
\end{aligned}
$$

As in Chapter II, the last equation is neglected, which assumes that heat transfer from the chamber walls to the model and prototype may be neglected and that the model cannot "see" itself. Substituting the dimensional relationships for the flat plat areas, there is obtained:

$$
\begin{aligned}
& q^{\prime \prime \prime *}=\frac{\mathrm{k}^{*} \mathrm{~T}^{*}}{\mathrm{~L}^{*+2}} \\
& \mathrm{q}^{\prime \prime *}=\frac{\mathrm{k}^{*} \mathrm{~T}^{*}}{\mathrm{~L}^{*}}
\end{aligned}
$$




$$
\begin{aligned}
& q^{*}=k^{*} \mathrm{t}^{*} \mathrm{~T}^{*} \\
& \theta^{*}=\left(\rho_{\mathrm{c}}\right) * \frac{\mathrm{I}^{* 2}}{\mathrm{k}^{*}} \\
& \mathrm{~T}^{*}=\left(\frac{t^{*} \mathrm{~K}^{*}}{\mathrm{I}^{* 2}}\right)^{1 / 3}
\end{aligned}
$$

The Method 2 parameters are based on the assumptions:

$$
\begin{aligned}
k=k_{0} T^{a} & \left(T={ }^{\circ} R\right) \\
c_{p}=c_{p_{0}} T^{b} & \left(T={ }^{\circ} R\right)
\end{aligned}
$$

Using these relationships and further assuming that model and prototype are to be made of the same material, Equations (A-21) through (A-25) may be re-written as:

$$
\begin{aligned}
q^{\prime \prime *} & =\left[\frac{t^{*}(1+a)}{L^{*}}\right]^{\frac{1}{3-a}} \\
q^{\prime \prime} & =\left[\frac{t^{*}(1+a)}{L^{*}(5+a)}\right]^{\frac{1}{3-a}} \\
\therefore q^{*} & =\left[\frac{t^{* 4}}{L^{*}(1+a)}\right]^{\frac{1}{3-a}} \\
\theta^{*} & =\left[\frac{t^{*}(b-a)}{L^{*}(2 b-6)}\right]^{\frac{1}{3-a}} \\
T^{*} & =\left[\frac{t^{*}}{I^{* 2}}\right]^{\frac{1}{3-a}}
\end{aligned}
$$

Method 3 assumed that the thermal conductivity and specific heat did not vary with temperature, which is to say that $a=b=0$. The Method 3 parameters may then be written immediately from the Method 2 Equations (A-26) 
through $(A-30)$.

$$
\begin{aligned}
& q^{\prime \prime \prime}=\left[\frac{t *}{L^{* 8}}\right]^{1 / 3} \\
& q^{\prime \prime} *=\left[\frac{t^{*}}{L^{* 5}}\right]^{1 / 3} \\
& q^{*}=\left[\frac{t^{* 4}}{L^{* 5}}\right]^{1 / 3} \\
& \theta^{*}=L^{* 2} \\
& T^{*}=\left[\frac{t^{*}}{L^{* 2}}\right]^{1 / 3} .
\end{aligned}
$$

As with the Method 1 parameters, the only Method 2 and 3 flat plate parameter which differs from the corresponding solid cylinder parameter is the one for conduction heat transfer, $q^{*}$ 。

The flat plate similarity parameters for the three methods are presented in Table XVI。

A hollow cylinder with the principal conduction heat transfer direction parallel to the cylinder axis, and with wall thickness $t$, may also be described by these same parameters. The ratio of areas normal to the conduction heat transfer direction and the ratio of surface radiation areas may be described by the equations:

$$
\begin{aligned}
& A_{n}{ }^{*}=t^{*} D^{*} \\
& A_{S}{ }^{*}=D^{*} L^{*}
\end{aligned}
$$


As before, the length and diameter must be equally scaled (i.e., $L^{*}=D^{*}$ ), which resultis in the equations being written as:

$$
\begin{aligned}
& A_{n}^{*}=t^{*} L^{*} \\
& A_{S}^{*}=I^{* 2} .
\end{aligned}
$$

These are identical to Equations $(A-1)$ and $(A-2)$ so the parameters in Table XVI apply equally to hollow cylinders. These parameters are the same as those derived by Adkins (9) in a completely different manner. 
THE SIMILARITY PARAMETERS FOR FLAT PLATE

AND HOLLOW CYLINDRICAL SYSTEMS

\begin{tabular}{|c|c|c|c|}
\hline Parameter & Method 1 & Method 2 & Method 3 \\
\hline$q^{\prime \prime \prime} *$ & $I^{*-2}$ & {$\left[\frac{t^{*}(1+a)}{L^{8}}\right]^{\frac{1}{3-a}}$} & {$\left[\frac{t *}{L * 8}\right]^{\frac{1}{3}}$} \\
\hline$q^{\prime \prime} *$ & $I *-1$ & {$\left[\frac{t^{*}(1+a)}{L^{*}(5+a)}\right]^{\frac{1}{3-a}}$} & {$\left[\frac{t^{*}}{L^{*}}\right]^{\frac{1}{3}}$} \\
\hline$q^{*}$ & $I^{* 2}$ & {$\left[\frac{t^{4}}{I * 2(1+a)}\right]^{\frac{1}{3-a}}$} & {$\left[\frac{t^{*}}{L * 5}\right]^{\frac{1}{3}}$} \\
\hline $\mathrm{T} *$ & 1 & {$\left[\frac{t *}{I^{*}{ }^{2}}\right]^{\frac{1}{3-a}}$} & {$\left[\frac{t^{*}}{L^{* 2}}\right]^{\frac{1}{3}}$} \\
\hline$\theta *$ & $I * 2$ & {$\left[\frac{t^{*}(b-a)}{L^{*}(2 b-6)}\right]^{\frac{1}{3-a}}$} & $\mathrm{~L}^{* 2}$ \\
\hline$t^{*}$ & $I * 2$ & - & - \\
\hline$t^{*}$ & $D * 2$ & $\begin{array}{l}\text { (for hollow cylindrical } \\
\text { only) }\end{array}$ & system \\
\hline
\end{tabular}




\author{
VITA \\ Paul LeRoy Miller, Jr。 \\ Candidate for the Degree of \\ Doctor of Philosophy
}

Thesis: THERMAL MODELING IN A SIMULATED SPACE ENVIRONMENT

Major Field: Mechanical Engineering

Biographical:

Personal Data: Born June 27, 1934, in Guthrie, Oklahoma, the son of Paul L. and Minnie A. Miller.

Education: Received the Bachelor of Science degree and Master of Science degree from Kansas State University, with major in Mechanical Engineering, in January, 1957 and January, 1961, respectively. Completed the requirements for the Degree of Doctor of Philosophy in July, 1966.

Professional Experience: Employed by Kansas State University from January, 1957 to May, 1965 as Instructor and Assistant Professor of Mechanical Engineering. Service in the U.S. Army from June, 1957 to February, 1958 was included in this time period. Summer employment with the Mobil Oil Company, 1955 and 1956, and Argonne National Laboratory in 1962. Recipient of a National Science Foundation Summer Institute Fellowship in 1961 and a National Science Foundation Graduate Traineeship in 1965-66. Employed by the School of Mechanical Engineering, Oklahoma State University as a Teaching Assistant during 1964-65 and as a Research Assistant during 1965-66.

Professional Organizations: Member of the American Society for Engineering Education, the Society of the Sigma Xi, Sigma Tau, and Pi Tau Sigma, Licensed Professional Engineer, State of Kansas.

Publications: "Reduction of Vapor Carryunder in Simulated Boiling,"Argonne National Laboratory Report No. 6674, February, 1963, (with C.P. Armstrong). 